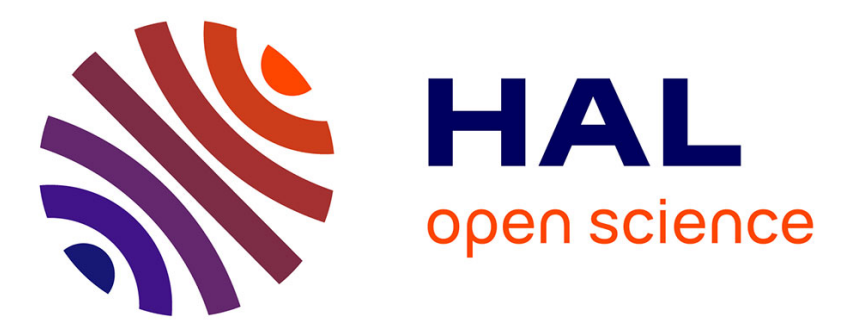

\title{
A journey through the emergence of nanomedicines with poly (alkylcyanoacrylate) based nanoparticles
}

\author{
Christine Vauthier
}

\section{To cite this version:}

Christine Vauthier. A journey through the emergence of nanomedicines with poly (alkylcyanoacrylate) based nanoparticles. Journal of Drug Targeting, 2019, 27 (5-6), pp.502-524. 10.1080/1061186X.2019.1588280 . hal-02359395

\section{HAL Id: hal-02359395 \\ https://hal.science/hal-02359395}

Submitted on 12 Nov 2019

HAL is a multi-disciplinary open access archive for the deposit and dissemination of scientific research documents, whether they are published or not. The documents may come from teaching and research institutions in France or abroad, or from public or private research centers.
L'archive ouverte pluridisciplinaire HAL, est destinée au dépôt et à la diffusion de documents scientifiques de niveau recherche, publiés ou non, émanant des établissements d'enseignement et de recherche français ou étrangers, des laboratoires publics ou privés. 


\title{
A journey through the emergence of nanomedicines with poly(alkylcyanoacrylate) based nanoparticles
}

\author{
Christine Vauthier*
}

Institut Galien Paris Sud, UMR CNRS 8612, Université Paris-Sud

92296 Chatenay-Malabry Cedex, France

\author{
*Corresponding author \\ Institut Galien Paris Sud, UMR CNRS 8612, Université Paris-Sud \\ 5 Rue J.B. Clément \\ 92296 Chatenay-Malabry Cedex, France \\ E.mail : Christine.vauthier@u-psud.fr
}




\section{Abstract}

Starting in the late 1970s, the pioneering work of Patrick Couvreur gave birth to the first biodegradable nanoparticles composed of a biodegradable synthetic polymer. These nanoparticles, made of poly(alkylcyanoacrylate) (PACA), were the first synthetic polymer based nanoparticulate drug carriers undergoing a phase III clinical trial so far. Analyzing the journey from the birth of PACA nanoparticles to their clinical evaluation, the paper highlights their remarkable adaptability to bypass various drug delivery challenges found on the way. At present, PACA nanoparticles includes a wide range of nanoparticles that can associate drugs of different chemical nature and be administered in vivo by different routes. The most recent technologies giving the nanoparticles customized functions could also be implemented on this family of nanoparticles. Through different examples, the paper discusses the seminal role of the PACA nanoparticles' family in the development of nanomedicines.

Key words: poly(alkylcyanoacrylate) nanoparticles, Drug delivery, drug targeting, cancer, clinical trials. 


\section{Abbreviations}

API: active pharmaceutical ingredient

Apo: apolipoprotein

ASODN: antisense oligodeoxynucleotide

BBB: blood brain barrier

CARPA: Complement activation-related pseudoallergy

DHAD-PIBCA nanoparticles: mitoxanthrone (dihydroxyanthracenedione) loaded -poly(isobutyl cyanoacrylate) nanoparticles

Dox-PIHCA nanoparticles: doxorubicin loaded-poly(iso hexylcyanoacrylate) nanoparticles

EPR: Enhance permeability and retention

HCC: hepatocellular carcinoma

PACA: poly(alkylcyanoacrylate)

PCL: poly( $\varepsilon$-caprolactone)

PEG: poly(ethylene glycol)

P(HDCA-co-MePEGHDCA): copolymer composed of hexadecyl cyanoacrylate and Methoxy PEGhexadecyl cyanoacrylate

PLA: poly(lactic acid)

PLGA: poly(lactic-co-glycolic acid)

siRNA: small interfering RNA 


\section{Summary}

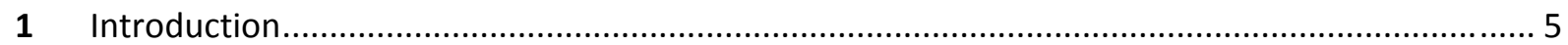

2 Birth of biodegradable polymer nanoparticles to serve as drug delivery vehicles ........................ 7

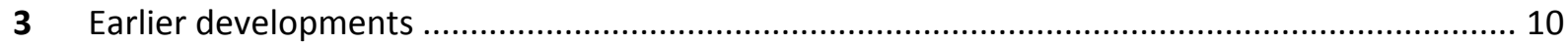

$4 \quad$ Exploring drug delivery potential of PACA nanoparticles. ...................................................... 13

4.1 Designing suitable nanotechnologies for drugs of different chemical nature........................ 15

4.2 Designing nanoparticles controlling their in vivo drug delivery performances ..................... 18

4.2.1 Manipulating the biodistribution of intravenously injected nanoparticles: the way to

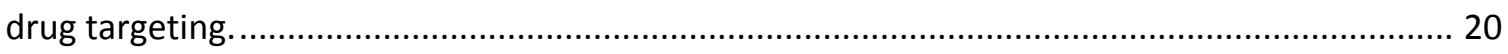

4.2.2 Enhancing drug delivery through physical biological barriers .................................... 24

4.3 Exploring potential of polymer nanoparticles to treat diseases: the way to the birth of nanomedicines

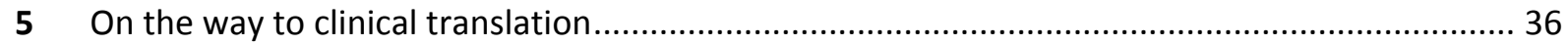

6 Overlook on current ongoing works on PACA nanoparticles ..................................................... 40

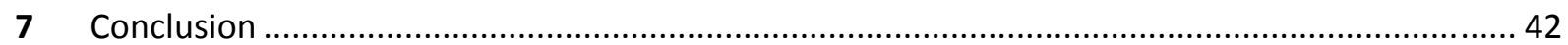

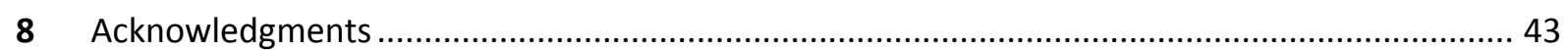

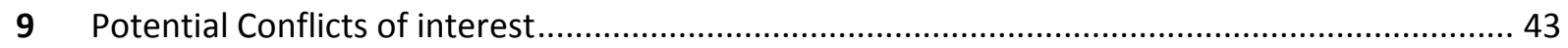

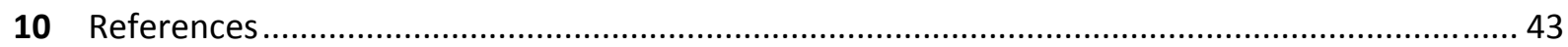




\section{Introduction}

Today, nanomedicines encompass cutting edge applications of nanotechnologies in many areas [Shi et al. 2010, Pelaz et al. 2017]. Drug development is one of the various fields in which applications of nanotechnologies in health care are holding promises. Short comings associated with molecules that face development challenges can be solved when they are associated with nanosized devices serving as delivery systems. Using this approach, poorly water-soluble molecules can become suitable candidate for development while initially considered as undevelopable. Active pharmaceutical ingredients (APIs) derived from biomolecules are also highly concerned by the technology having two unavoidable roles including a protection of the molecules against rapid degradation in biological media and a transport system to help the molecules to reach their intracellular target counterparts [Juliano, 2016, Park et al., 2016]. Nanotechnologies have also the potential to give a more desirable pharmacological property to an API (solubility, pharmacokinetics and biodistribution) without modifying its initial chemical structure. This remarkable property overcomes limitations found with conventional medicines. It is exploited in most works aiming to improve the specificity of the distribution of the API towards its target site and helping an API to bypass important physiological barriers found on the way to its target site [Blanco et al. 2015, Ross et al., 2015, Anchordoquy et al., 2017]. Improvements of spatial and temporal precisions of drug delivery can benefit to new molecular entities and "old" APIs. In some examples, the engineered carrier enables greater accumulation of the API at the target site while the administered dose can be reduced [Ventola, 2017]. With other APIs, the main benefits come from an increase of their safety profile thanks to a modification of the pharmacokinetics and biodistribution compared to those obtained using conventional drug formulations [Barrenholz, 2012]. The potential of nanomedicines in healthcare is much wider than considering them as simple delivery vehicles improving in vivo performances of APIs. The nanotechnology can be considered as the active species either because it displays an intrinsic activity or because the activity comes from the nanoconstruct [Lherm et al., 1987, Arias et al., 2011, Duncan 
and Gaspar, 2011, von Maltzahn et al., 2011, Bui et al., 2014, Pradine et al., 2015a, Lacombe et al., 2017]. Other opportunities come from the design of multifunctional nano-objects. For instance, in theranostic nanoparticles, a single nano-object combines a diagnostic and a therapeutic function that can provide with an in-situ monitoring of the efficacy of the treatment [Lammer et al., 2010, Reddy and Couvreur, 2011, Bui et al., 2014, Mura and Couvreur 2012, 2016a, Agrawal et al., 2013, Kunjachan et al., 2015, Hassanzadeh et al., 2018]. Today, nanomedicines have taken an important place in research to propose new treatments for patients. Very few compounds were approved so far to treat cancer and to fight against severe infections, but the number of projects translated in human clinics over the past few years has considerably grown [Anselmo and Mitragotri, 2016, Bobo et al., 2016, Caster et al., 2016, Bulbake et al., 2017, Lee Ventola, 2017, Lee et al., 2017, Li et al., 2017, Cicha et al., 2018]. Most ongoing clinical trials concern treatments of various cancers caused by solid tumors. In general, nanomedicines are developed as drug delivery systems, but several projects concern nanomaterials to be used in cancer radiotherapy [Hainfeld et al., 2014, Mi et al., 2016, Lacombe et al., 2017, Lamch et al., 2018]. Beside treating cancers and infections, nanomedicines hold promise to improve the life of patients suffering from brain diseases [Andrieux and Couvreur, 2013, Kreuter, 2014, Savaira et al., 2016, Zhou et al., 2018], cardiovascular diseases [Ferreira et al., 2015, Suarez et al., 2015, Varna et al., 2015, Chan et al., 2018, Cicha et al., 2018, Dormont et al., 2018] and metabolic diseases [Pridgen et al., 2015, Aguirre et al., 2016, Lakkireddy et al., 2016, Wong et al., 2017]. Many challenges remain to further accelerate the translation of nanomedicines in clinics [Blanco et al. 2015, Dusinska et al., 2015, Satalkar et al., 2016a, Cicha et al., 2018, Lakkireddy and Bazile this volume, Su et al., 2018]. However, it can be pointed out that the rapid expansion of the field observed over the last 20 years took its roots from the visionary works of a few pioneers of the early 1970s' [See historical perspectives from Kreuter et al., 2007, Alonso and Couvreur, 2012, Barrenholz, 2012]. The present paper is dedicated to one of these pioneers, Patrick Couvreur. It analyzes progresses made over time taking a journey across the developments of the first drug delivery vehicles based on biodegradable polymer nanoparticles. The first part entitled "birth of biodegradable polymer nanoparticles to serve as drug 
delivery system" takes its references from the scientific context in which Patrick Couvreur has found his way to polymer nanoparticles and to poly(alkylcyanoacrylate) (PACA) nanoparticles to propose the first biodegradable polymer nanoparticles. Then, the paper summarizes the journey of PACA nanoparticles from their birth to their clinical evaluation. It shows how PACA nanoparticles were adapted over time to answer the various drug delivery challenges and attempts to analyze how this family of nanoparticles in combination with other pioneer nanotechnologies have contributed to the current development of nanomedicines.

\section{Birth of biodegradable polymer nanoparticles to serve as drug}

\section{delivery vehicles}

Looking back 45 years behind, the term "nanomedicine" did not exist [see Krukemeyer, 2015]. However, the general idea that the performance of a medicine could be improved if the molecule can reach and interact better with its target site was already established. This idea was introduced at the beginning of the 20th century by Paul Ehrlich, laureate of the Nobel Prize in Medicine and Physiology in 1908 through his concept of the "Magic bullet" [Ehrlich, 2008]. It was originally imagined as a mean to promote interactions of chemotherapeutic agents with corresponding specific receptors involved in the battles against diseases [Bosch and Rosich, 2008, Stretbhardt and Ullrich, 2008, Valent et al., 2016]. It gave birth to the concept of drug targeting and was associated later with various drug delivery methods including approaches using drug carriers [Couvreur and Vauthier, 2006, Hoffman 2008, Karra and Benita, 2012].

Over the years 1950-1960s' tremendous progresses were made in the comprehension of the cell structure and intracellular organization [De Duve, 1974]. Thanks to massive arrival of electron microscopes in laboratories it also became possible to observe structures at the nanometer scale [see for instance Taxi, 1960, Couplan, 1965]. The Nobel Laureate in Medicine and Physiology 1974, Christian De Duve, was working on intracellular vesicles called lysosomes. In a paper entitled "Lysosomotropic 
agents" published in 1974, he underlined the role of the lysosomes in physio-pathology mechanisms behind major health threats including severe infections, leukemia and cancer: "Lysosomes are involved in many pathological situations, and our growing understanding of this role has brought to the light the need in therapeutics for lysosomotropic agents endowed with certain well-defined properties." [De Duve et al., 1974]. He has suggested that lysosomotropism can be "conferred artificially on almost any substances, by suitable coupling with an appropriate carrier." [De Duve et al., 1974]. The role and properties of the carrier was then explained in detail.

At this time, very few laboratories considered the use of drug carriers to improve in vivo performance of existing APIs thanks to a more adequate delivery profile. Few drugs were associated with proteins such as antibodies or with DNA serving as lysosomotropic carriers [see De Duve et al., 1974 for references] or coupled with synthetic hydrosoluble polymers [see for references: Ringsdorf, 1975, Kopecek and Kopeckova, 2010]. In general, the API was coupled to carrier through covalent linkage limiting the number of copies of API molecules that could be attached with the carrier. Another option consisted of the encapsulation/entrapment of APIs into tiny engineered vesicles or particles. By this approach, the chemical structure of the API was untouched, and many copies of the molecules could be transported by each particle. Tiny vesicles, called liposomes, were available in the early 1970s'. They were isolated in the mid-1960s' by Alec Bangham who studied exchanges of ions and molecules across the lipid bilayer that formed a barrier between the inner core of those vesicles and the outside medium mimicking exchanges occurring across the membrane of the cells [Bangham et al., 1965, Gregoriadis, 2018]. In the early 1970s', Gregory Gregoriadis at the Clinical Research Center, Middlesex in the United Kindom has initiated a work exploring the potential of these lipid vesicles to serve as drug delivery systems [Gregoriadis 1973, 2018, Perrie, 2008]. At the same period, at the Swiss Federal Institute of Technology [ETH] in Zurich, Switzerland, Peter Speiser and his group were working on the synthesis of non-liposomal colloidal size range polymer nanoparticles to serve as drug carriers and vaccine adjuvants [Birrenbach and Speiser, 1976, Kreuter 1974, see also Speiser, 1979 and Kreuter, 2007 for references]. In this emerging scientific context linked to pharmaceutical sciences, Patrick 
Couvreur, a young pharmacist, completed his doctoral thesis in Pharmacy at the University of LouvainLa-Neuve in Belgium on the disintegration mechanism of pharmaceutical tablets. This subject was in line with the current interest in pharmaceutical technologies which had just turned into a more scientific based discipline thanks to the contribution of Takeru Higushi "The Father of Physical Pharmacy" [Stella, 2001, Puisieux and Barratt, 2011]. Next to the pharmaceutical technology laboratory was the cell biology laboratory of Christian De Duve in which works on the functionality of lysosomes and on the understanding of their role in physio-pathological processes were pursued [De Duve et al., 1974]. Scientists from both labs and different disciplines including pharmacists, biologists and medical doctors used to meet at lunch time [See interview by Stanwix, 2014]. Across informal discussions, the curiosity of Patrick Couvreur was awakened for what they altogether called "nanopills" imagined as possible vehicles to drag non-intracellularly diffusible drugs into the cell interior and more specifically into lysosomes. This idea became a source of inspiration for Patrick Couvreur who decided to initiate a breakthrough project in pharmaceutical technology which goal was to design lysosomotropic "nanopills" [See interview by Stanwix, 2014]. This project became later the driving son of his career. Given the current development of nanomedicines, the challenge deserved his interest. Patrick Couvreur was among the very first scientists who took this turn when he decided to join the group of Professor Peter Speiser at ETH in Zurich in the mid-1970s. This also marked the start of a crucial collaboration.

In his first work, Patrick Couvreur synthesized fluorescein loaded "nanocapsules" and demonstrated their potential to deliver the entrapped fluorescent molecules in lysosomes, the intracellular compartment where drugs were needed in cells according to the work of De Duve et al. [De Duve et al., 1974, Couvreur et al., 1977]. The results were promising but the non-biodegradability of the polymer composing the nanoparticles was an obstacle to pursue their development as injectable pharmaceutics for an application in human clinic. The next step was to obtain biodegradable nanoparticles. Discussing with surgeons at the University Catholique de Louvain where he returned after his Post-Doc, Patrick Couvreur's attention was retained by a surgical glue made of a monomer 
giving a biodegradable polymer upon polymerization. This information gleaned from new discussions with researchers of a different background from his own, gave him a solution to try to convert previously synthesized nanoparticles into a biodegradable species. From few drops of alkylcyanoacrylate, the monomer composing the surgical glue borrowed from surgeons of the institute, he synthesized the first biodegradable nanoparticles made of polymer and demonstrated that they were able to associate drugs [Couvreur et al., 1979]. This work marked a milestone. It immediately raised a growing interest to polymer nanoparticles as potential drug delivery system and, later, have paved the way for clinical trials [Oppenheim, 1981, Couvreur, 1984, 1988, Kreuter, 1983, 1988, Douglas et al., 1987, Kattan et al. 1992, Soma et al., 2012, Zhou et al., 2009, NCT01655693]. The context in which this initial work was completed was favourable for the development of polymer-based drug carriers. Difficulties were found with the early liposomes that were leaky and not enough stable in biological media [See Barrenholz, 2012]. Thus, polymer nanoparticles were considered as alternative solutions to those liposomes assuming that they could be more stable in biological media.Earlier developments

The driving force behind Patrick Couvreur's project was to make a medicine available for patients. Therefore, he developed a scientific strategy that was aimed to complete essential steps for the development of new drugs with very clear objectives. Urgent steps to complete were (1) to demonstrate that the newly developed PACA nanoparticles can associate chemotherapeutic agents and release these agents where needed, (2) to investigate their safety, (3) to show that the nanoparticles can be injected in vivo without causing dramatic problems, (4) to establish the pharmacokinetics and biodistribution profile of a drug associated with the nanoparticles postulating that it will differ significantly from that of the free drug improving its safety profile and pharmacological activity, (5) to show that they were degradable and can be eliminated from the body. It is noteworthy that working to address these aspects appears very obvious and basic with our current knowledge. However, looking back, this was an ambitious project as nothing was known about the fate of manmade nanotechnologies in the human body. No method existed hence pioneers had tremendous work 
to imagine and set methodologies to progress in their work. Results from such preliminary series of work were eagerly awaited as they conditioned the continuation of the whole project towards clinical trials.

It can be noted that the work done to answer these early questions were completed in a relatively short period of time. Short after the first report describing the preparation, morphological and sorptive properties of the nanoparticles made from the polymerization of the surgical glue composed of alkylcyanoacrylate monomers [Couvreur et al., 1979a], a second paper has reported association of antineoplastic agents and their release in serum [Couvreur et al., 1979b]. In parallel to publishing the results in the scientific literature to make them available to the scientific community, patents were immediately filled in Belgium and Europe to protect the invention and were extended later in France and in the United states [Couvreur et al., 1979c, 1979d, 1981, 1982a]. Before, nanoparticles made of poly(lactic-co-glycolic acid), the second type of biodegradable nanoparticles made of a synthetic polymer, appeared on the scene [Gurny et al., 1981], tissue distributions of drugs associated with various species of PACA nanoparticles were also reported [Couvreur et al., 1980a, Kante et al., 1980]. At this stage, a set of promising results were already obtained encouraging the continuation of the development of the PACA nanoparticles as potential drug carriers to be used in human healthcare. More drugs including anticancer agents [vinblastine, actinomycin D, methotrexate and daunorubicin], an antibiotic, (penicillin V) and an antiparasitic agent [levamisole] were associated with the nanoparticles [Couvreur et al., 1980b]. Pharmacokinetics and biodistributions of actinomycin D and vinblastine reported after intravenous injection to rats in their nanoparticle formulation were frankly different from that of the free drugs [Couvreur et al., 1980a, Kante et al., 1980]. Consistently to what was generally observed with liposomes [Gregoriadis et al., 1973, 1977], a large percentage of the injected dose of the drug associated with the nanoparticle formulations accumulated in the liver and spleen that was explained later [Couvreur et al., 1980a, Kante et al., 1980]. Importantly, these results demonstrated that PACA nanoparticles could be injected to animals without producing deleterious effects that would have compromised further developments. In the last steps of the earlier age 
development, it was aimed to demonstrate that the nanoparticles were non-toxic on their own and could be degraded in vivo. Acute toxicity was investigated at the cellular and whole-body animal levels. None of the results obtained so far compromised the use of PACA nanoparticles in the perspective of their application in human clinic [Kante et al., 1982]. Important results came out from a study reporting the in vivo fate of doxorubicin delivered by intravenously injected drug-loaded nanoparticles. The general toxicity of this drug, doxorubicin, was significantly reduced by fixing it to PACA nanoparticles as acknowledged by a reduction of the mortality as well as the weight loss of the mice. The cardiotoxicity of doxorubicin which is a tremendous limit treating patients [Thorn et al., 2011] was clearly diminished when this drug was administered to mice in the PACA nanoparticle formulation [Couvreur et al., 1982b]. This result marked a new milestone providing the proof of concept that drug molecules can be delivered with nanoparticles made of degradable polymers reducing their toxic effects. Degradation of the PACA nanoparticles was investigated considering different physicochemical environments $[\mathrm{pH}]$ and the action of esterase's extracted from microsomes. It was assumed that the main mechanisms of degradation occurring in vivo would consist in the cleavage of the ester bond of the alkylcyanoacrylate residue by esterases causing the dissolution of the nanoparticles in the late endosomes inside cells. Assumptions drawn on the mechanism of degradation of the PACA nanoparticles were verified [Leyh et al., 1984, Lenaerts et al., 1984]. Interestingly, the release of a drug associated with the nanoparticles was concomitant to nanoparticle degradation [Lenaerts et al., 1984]. The drug carrier being mainly degraded by esterase's showed ideal properties to release its cargo once it has reached the lysosomes, the targeted intracellular compartment through the overall drug delivery strategy followed during these early works.

The potential of PACA nanoparticles as suitable drug carriers for applications in human medicine was consolidated. The proof of concept was validated, and enough results were accumulated to move on to the next step. Meanwhile, the remarkable results published in the literature by Patrick Couvreur and his colleagues have convinced other scientists to start exploring the drug delivery potential of nanoparticles composed of PACA from 1983 onwards [Kreuter 1983a,b, Illum et al. 1983, 1984, 
Couvreur et al., 1983a, 1988, Douglas et al., 1986, El-Samaligy et al., 1986, Gasco and Trotta, 1986]. Since then, together with nanoparticles made of PLGA, the PACA-based nanoparticles were considered in a considerable number of works to resolve drug delivery challenges [Couvreur et al., 1984, 1988, 1990,1991, Kreuter, 1988, 1994, Couvreur and Vauthier, 1991, 2006, Fattal et al., 1998, Vauthier et al., 2003a,b, 2007, Murthy and Reddy, 2006, Mundargi et al., 2008, Andrieux and Couvreur 2009b, Graf et al., 2009, Nicolas and Couvreur, 2009, Nicolas and Vauthier, 2011, Danhier et al., 2012, Yordanov, 2012, Lai et al., 2014, Alonso and Couvreur, 2012, James et al., 2016, Lakkyreddy and Bazile, 2016, Lee et al., 2016, Tyler et al., 2016, Bawa and Oh, 2017].

\section{Exploring drug delivery potential of PACA nanoparticles.}

Results obtained from preliminary evaluations of PACA nanoparticles were promising to progress towards the development of nanoparticulate drug carriers using PACA and resolve challenges found in drug delivery. From this point, nanoparticles made of PACA were considered as potential drug carrier by researchers all around the world (Figure 1). Patrick Couvreur continued his researches on PACA nanoparticles at the Faculty of Pharmacy of the University of Paris-Sud. He was appointed as a full Professor and has joint the laboratory headed by Francis Puisieux where works on liposomes were ongoing (See Vauthier et al., 1999).

At the beginning, the general purpose for the use of a drug carrier was to provide known API, i.e. the "old" drugs, with a more appropriate pharmacokinetic and biodistribution profile leading a more efficient distribution at the target site promoting biological efficacy and reducing side effects. This is still the aim of many current works. Besides, new APIs appeared on the scene over the past 40 years. Drug candidates that came out of discovery pipelines of the pharmaceutical industry in the 1990s' were molecules with a poor solubility profile that needed specific formulation efforts [Kaleku and Nekkanti, 2015, Zhang et al., 2018, Van Hoogevest et al., 2011, Narvekar et al., 2014, Zhang et al. 2018]. 


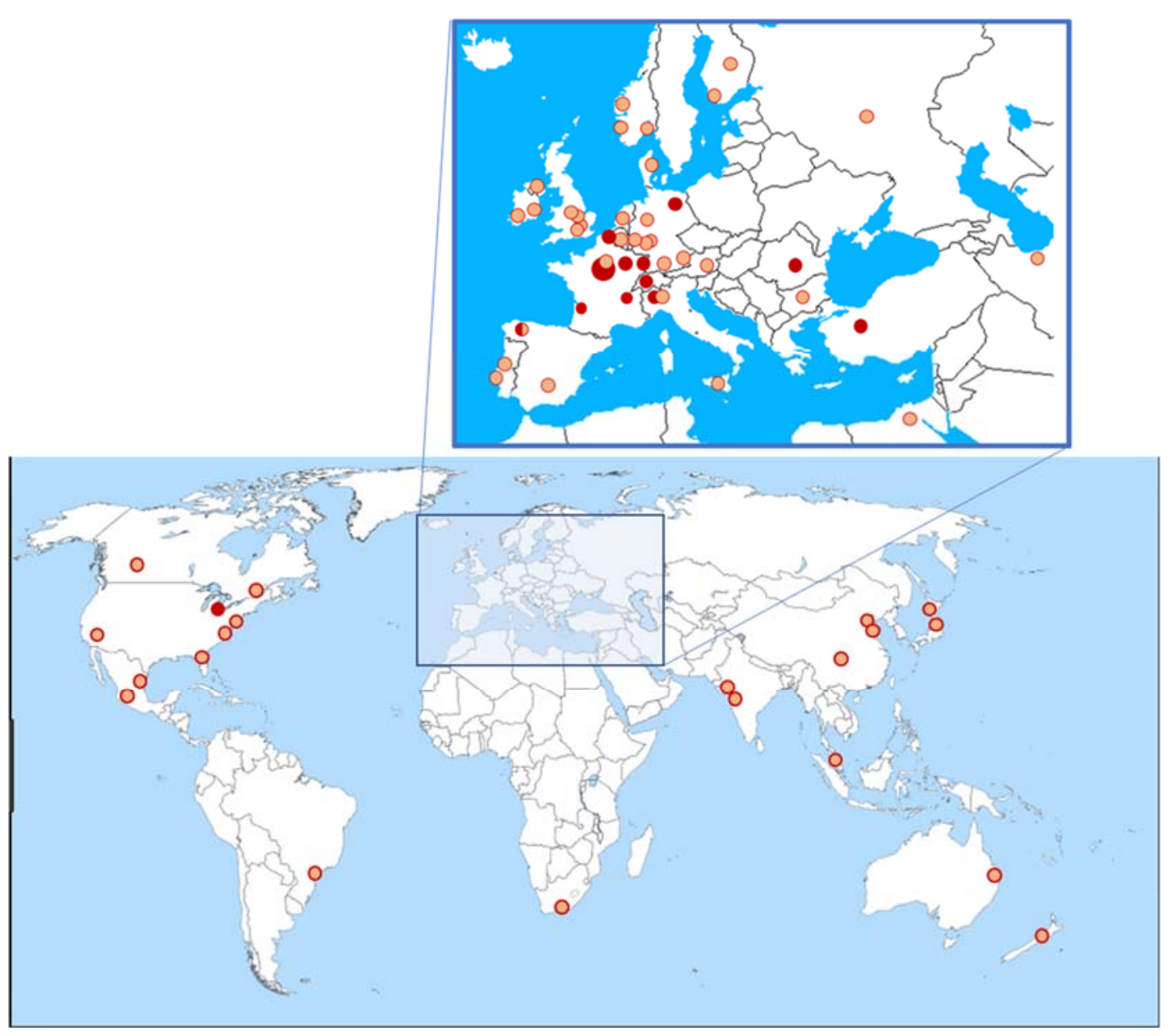

Figure 1: As this map shows, works having considered PACA-based nanoparticles as nanomedicines were published from different regions of the world. Dark spots: teams having co-published with Patrick Couvreur. Light spots: teams having worked independently.

Their association with polymer nanoparticles was considered between different options to resolve problems linked to their low solubility in biological media causing a low biodisponibility or hindering their clinical development. Alongside this, novel strategies to design treatments for cancer, infections and neurodegenerative diseases that remained without satisfactory solutions for patients have emerged from molecular and cellular biology and immunology advances which provided with a better understanding of biological processes behind pathological disorders. New APIs were needed comprising biomolecules such as peptides or proteins, i.e. monoclonal antibodies and nucleic acids. They are active at a low dose and their mode of action is highly specific. However, their in vivo delivery to obtain active treatments is challenging because of their low stability in biological media and poor 
diffusion across biological barriers, in particular the cell membrane which is an obstacle to reach the API target located in the cell cytoplasm or nucleus [Couvreur and Puisieux, 1993, Couvreur et al., 1993, Fattal et al., 1998, Mahato, 2000, Chung et al., 2012, Silva et al., 2015, Juliano et al., 2016, Lakkireddy et al., 2016, Anselmo et al., 2018]. Over the years, Patrick Couvreur has explored the potential of the nascent nanotechnologies using PACA nanoparticles to resolve drug delivery hurdles facing known and new challenges [Damgé et al., 1988, Chavany et al., 1992, Couvreur and Puisieux, 1993, Fattal et al., 1998, Fattal and Couvreur, 2000]. His contribution to the different challenges was summarized in the next few paragraphs. As new molecules appeared as potential drugs, one challenge was to have drug carriers that could suit to the different types of drugs. Approaches to design nanocarriers suitable for various drug molecules were exposed in the paragraph 4.1: Designing nanotechnologies suitable for drugs of different chemical nature. Approaches developed to control the in vivo fate of polymer were described in the paragraph 4.2.: Designing nanoparticles controlling their in vivo drug delivery performance. This paragraph explained progresses made towards the conception of targeted nanoparticles and gives a few examples of the use of nanoparticles to go across major physiological barriers that are hurdles to the efficacy of many treatments.

\subsection{Designing suitable nanotechnologies for drugs of different chemical nature.}

Successful association of drugs with a carrier made of polymer nanoparticles generally depends on both the nature of the polymer composing the carrier and the API physicochemical characteristics [Charrueau and Zandanel, 2016]. Over the years, projects exploring drug delivery potential of polymer nanoparticles were multiplied and diversified to answer various needs designing better treatments for patients. This has confronted technologies based on polymer nanoparticles to the challenge of associating a wide range of biologically active molecules. Results obtained from early evaluations of nanoparticles made of PACA have encouraged their selections as potential drug carrier candidate in many new projects. As these nanoaprticles were quite easy to produce, the technology was considered in many laboratories. Unexpectedly, these nanoparticles were suitable for wide range of drugs. Today, PACA-based nanoparticles comprise a large family having different features that allows association of 
"old" and new APIs occurring as small or large molecules being hydrosoluble, lipophilic or belonging to the poorly soluble species [Nicolas and Couvreur, 2009, Vauthier, 2016] (Table 1).

\begin{tabular}{|c|c|c|c|}
\hline $\begin{array}{l}\text { Type of } \\
\text { nanoparticle }\end{array}$ & Method of synthesis & $\begin{array}{l}\text { Method of drug } \\
\text { association }\end{array}$ & $\begin{array}{l}\text { Type of drugs associated } \\
\text { with nanoparticles }\end{array}$ \\
\hline Nanc & $\begin{array}{l}\text { Anionic/zwitterionic } \\
\text { emulsion } \\
\text { polymerization } \\
\text { [Couvreur et al., 1979a] }\end{array}$ & $\begin{array}{l}\text { Association during } \\
\text { polymerization }\end{array}$ & 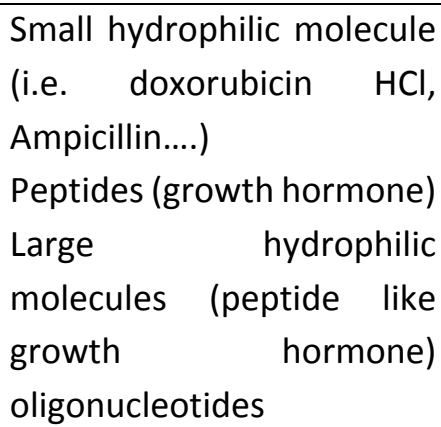 \\
\hline Nanosp & $\begin{array}{l}\text { Radical polymerization } \\
\text { [Chauvierre et al., 2003] }\end{array}$ & $\begin{array}{l}\text { Adsorption after } \\
\text { polymerization: }\end{array}$ & $\begin{array}{l}\text { Small hydrophilic molecule } \\
\text { (i.e. doxorubicin), large } \\
\text { hydrophilic molecules (i.e. } \\
\text { oligonucleotides) }\end{array}$ \\
\hline $\begin{array}{l}\text { Oil-containing } \\
\text { nanocapsules }\end{array}$ & $\begin{array}{l}\text { Interfacial } \\
\text { polymerization in oil-in- } \\
\text { water emulsion } \\
\text { obtained by the Ouzo } \\
\text { effect or miniemulsions } \\
\text { [Al Khouri et al., 1986, } \\
\text { Damgé et al., 1988] }\end{array}$ & $\begin{array}{l}\text { Encapsulation during } \\
\text { formation of the } \\
\text { nanocapsules }\end{array}$ & $\begin{array}{lr}\text { Large } & \text { hydrophilic } \\
\text { molecules (i.e. peptide like } \\
\text { insulin) } \\
\text { Small hydrophobic } \\
\text { molecules } \\
\text { indomethacin, pilocarpine, } \\
\text { carbamazepine, } \\
\text { daredipin...)) }\end{array}$ \\
\hline $\begin{array}{l}\text { Water-containing } \\
\text { nanocapsules }\end{array}$ & $\begin{array}{l}\text { Interfacial } \\
\text { polymerization in } \\
\text { water-in-oil emulsion, } \\
\text { miniemulsion or } \\
\text { microemulsions } \\
\text { [Lambert et al., 2000, } \\
\text { Watnasirichaikul et al., } \\
2000 \text { ] }\end{array}$ & $\begin{array}{l}\text { Encapsulation during } \\
\text { formation of the } \\
\text { nanocapsules }\end{array}$ & $\begin{array}{l}\text { Small water soluble } \\
\text { molecules: nucleotides } \\
\text { Large water soluble } \\
\text { molecules; peptides like } \\
\text { insulin, oligonucleotides. }\end{array}$ \\
\hline
\end{tabular}

Table 1: PACA-based nanoparticles with different features developed to answer the challenge of associating drugs of various physicochemical properties. [Reproduced with permission from Vauthier, 2016]. 
To answer challenges of associating drugs of various natures with nanoparticles, the contribution of Patrick Couvreur was not limited to nanoparticles composed of PACA. For instance, he has introduced the first hydrogel-based nanoparticles that were made of alginate [Rajaonarivony et al., 1993]. These nanoparticles are still investigated by several groups as potential carriers for peptides and nucleic acids and have raised interests beyond pharmaceutical applications [Sarmento et al., 2006, Hamidi et al., 2008, Ahmad et al., 2010, Venkatesen et al., 2016, Lopes et al., 2017, He et al., 2018, Mulhopadhyway et al., 2018]. The methodological approach developed to prepare these hydrogel-based nanoparticles inspired those used later to obtain chitosan-based nanoparticles [Calvo et al., 1997, Sarmento et al., 2007, Li et al., 2008] another type of nanoparticles currently considered to achieve peptides and small fragments of nucleic acids delivery [miRNA, siRNA...] delivery [Calvo et al., 1997, Li et al., 2008, GarciaFuente and Alonso, 2012, Vauthier et al., 2013, Islam and Ferro, 2016, Venkatesen et al., 2016, Key and Park, 2017, Mokhtarzadeh et al., 2017, Wang et al., 2017]]. Then, Patrick Couvreur has contributed to the invention of a method of fabrication of hydrogel-based nanoparticles through the formation of a complex between two polymers by a key-lock like system. The lock was a poly(cyclodextrin) polymer in which the cyclodextrin residues were hosts for the keys composed by alkyl chains grafted on a polysaccharide [Gref et al., 2006, Daoud-Mohammed et al. 2007, 2008]. Highly hydrophobic drug molecules such as tamoxifen and benzophenone could be associated with these nanoparticles thanks to their inclusion in cyclodextrin residues not involved in the building of the nanoparticle structure [Daoud-Mohammed et al., 2009]. Interest for this technology is currently pursued inspiring the design of new nanomaterials for applications in drug delivery [Mejia-Ariza et al., 2017, Wankar et al., 2017, Diaz-Salmeron et al., 2018]. The next innovation was the design of methodologies producing multifunctional nanotechnologies leading the way to nanotheranostics, a new field combining diagnostic and therapeutic activities within a single nano-object and to the design of new drug delivery platforms with improved delivery performances. One of the proposed platforms was obtained from the self-assembly of squalene derivatives bearing different functionalities including a high payload of the API, a targeting tool and a diagnostic agent [Couvreur et al., 2006, Reddy et al., 2007, Arias et al., 
2011, Reddy and Couvreur, 2011, Desmaële et al., 2012, Feng et al., 2017, Mura et al., this volume]. This novel concept designing nanoparticles was also applied a few years later to conceive multifunctional PACA-based nanoparticles [Nicolas et al., 2008, 2013, Le Droumadet et al., 2012]. Today, nanotechnologies based on self-assembly are the most advanced systems. Customized characteristics can be given to nanoparticles and a generally high loading capacity can be obtained with a wide range of APIs [Desmaële et al., 2012, Delplace et al., 2014, Nicolas, 2016, Feng et al., 2017, Mohammadi et al., 2017, Li et al., 2018, Yang et al., 2018]. These systems hold great promise to resolve several limitations found with simpler formulations of polymer-based nanocarriers which are a generally low payload and a poor control of the release of the cargo. The method of synthesis of the new generation of carriers based on self-assembly of molecules is robust and scalable. Different tools can be implemented to achieve a better control of the delivery of the drug in the target site. A system that triggers the release of the drug under well define circumstances generally found at the target site can be incorporated in the nanoparticles as well as targeting ligands to promote the recognition of the target cells. [Desmaële et al., 2012, Nicolas et al., 2008, Mura and Couvreur, 2012, Mura et al., 2013, Feng et al., 2017, Mohammadi et al., 2017, Hassansadeh et al., 2018, Yang et al., 2018].

\subsection{Designing nanoparticles controlling their in vivo drug delivery performances}

One of the aims of using drug carriers was to control better the biodistribution of APIs promoting their delivery at the target site. In early works, "old" anticancer and antimicrobial agents administered intravenously were obvious candidates for the application of the nascent drug delivery technologies which included liposomes and polymer nanoparticles [Gregoriadis, 1973, Couvreur et al., 1980a]. Today, developments are pursued considering "old" drug molecules and all APIs from the new generation including poorly soluble molecules and various biomolecules, i.e., peptides, proteins, nucleic acids. Drug delivery performances of polymer nanoparticles have been explored using almost all routes of administration [Cappel and Kreuter, 1991, Vauthier and Couvreur, 1991, Vauthier et al., 2003a, Mesiha et al., 2005, Ludwig et al., 2006, Alonso and Csaba, 2012, Fonte et al., 2015, Jonagam, 2017, Batista et al., 2018, Gedawy et al., 2018]. Whatever the route of administration, the success of 
the delivery method greatly depends on the passage through different barriers separing the site of administration from the target site [Alonso and Csaba, 2012, Duncan and Richardson, 2012, Blanco et al., 2015, Ross et al., 2015, Lundquist and Arturson, 2016, Anchordoquy et al., 2017, Dai et al., 2018]. The design of efficient drug carriers on rational basis is pending to the understanding of parameters that control their progression through the different barriers found on the way to the target site and of the biological environment of the disease (Schroeder et al., 2011, Duncan and Richardson, 2012, Lammers et al., 2012, Blanco et al., 2015, Hare et al., 2017). It currently remains a challenge to meet the full drug targeting promises expected from the use of nanotechnology-based drug carriers like polymer nanoparticles (Blanco et al., 2015, Anchordoquy et al., 2017, Dai et al., 2018). Nevertheless, since their initial development, a series of bottlenecks were unmasked and elucidated (Lammers et al., 2012, Blanco et al., 2015, Wicki et al., 2015, Ross et al., 2016). Thanks to their extreme adaptability, PACA nanoparticles were considered in many studies having explored hypotheses to achieve the goal of drug targeting. Their seminal role demonstrating proofs of concepts in drug targeting and to achieve drug delivery improvements can be pointed out. As summarized below, PACA nanoparticles were major players deciphering the design of targeted nanoparticles administered by intravenous injections (see section 4.2.1.). They were also major actors in works performed to lift drug delivery challenges through biological barriers opening the way to oral delivery of peptides (see section 4.2.2.1.), to deliver drugs in the brain barrier (see section 4.2.2.2.) and to the delivery of anticancer drugs in resistant cells (see section 4.2.2.3.). The strength of a large body of works done with PACA nanoparticles strands on studies based on clearly identified clinical perspectives having included in vivo evaluations on animal models of the corresponding diseases (see for instance Damgé et al., 1988, Fattal et al., 1989, Chiannikulchai et al., 1989, Chavany et al., 1992, Schwab et al., 1994, Brigger et al., 2004, Calvo et al., 2001a, Ramon et al., 2013, Juenet et al., 2017, Fusser et al., 2019). Following such an approach has been reminded as an urgent necessity to make progress in clinical translation of nanomedicines in recent articles analysing the clinical output of the considerable amount of works done on nanomedicines [Park, 2013, Venditto and Szoka, 2013, Dai et al., 2018]. Additional strength of works 
done on PACA nanoparticles comes from fundamental studies. Their mechanisms of action were deciphered in different situations (see for instance Balland et al., 1996, Collin de Verdièrre et al., 1994, Kim et al., 2007, Kreuter, 2014) and efforts have been made to elucidate how they were interacted with various biological systems (See for instance Peracchia et al., 1999, Brambilla et al., 2012, Coty et al., 2017, Sulheim et al., 2016, 2017). Results generated by such works are roots for the understanding of the in vivo efficacy and safety of nanomedicines. They provide numerous information for the development of the future generation of nanomedicines.

\subsubsection{Manipulating the biodistribution of intravenously injected nanoparticles: the way} to drug targeting.

Very first biodistribution studies of early liposomes and PACA nanoparticles have revealed that intravenously injected man-made nano-objects were sequestrated by the immune system of the host [Gregoriadis, 1977, Couvreur et al., 1980a, Kante et al., 1980, Oppenheim, 1981]. This found interest for targeting drugs to intracellularly infected macrophages [Fattal et al. 1989, Abed and Couvreur, 2014, Abeb et al., 2015, Jiang et al., 2018] and to other liver disease such as liver cancer [Chiannilkulchai et al. 1989, Reddy and Couvreur, 2011, Soma et al., 2012, Merle et al. 2015, Lu et al., 2018]. However, sequestration of nanoparticles by the immune system is a considerable obstacle to achieve drug delivery to disease tissues localized in organs that are not the main seats of the immune system. The addition of poly(ethylene glycol) (PEG) on the surface of nanomedicines, called PEGylation, was a major advance towards the design of nanoparticles being able to escape sequestration by macrophages. It was assumed to reduce the opsonization of the particles, a process which involved the adsorption of serum protein on the surface of the nanoparticles preparing them for their recognition or not by macrophages of the immune system [Jeon et al., 1991, Blume and Cveg, 1990, Gref et al., 1994, Bazile et al., 1995]. PEGylated PACA nanoparticles were obtained by different ways. The early PEGylation 
method consisted on the adsorption of a PEG containing surfactant such as poloxamin and poloxamer on the surface of pre-synthesized nanoparticles [Illum et al., 1983, Kreuter et al., 1995]. Later, PEG was chemically grafted to PACA-based polymers to strengthen the stability of the PEG layer formed at the nanoparticle surface. The PEGylation was achieved initiating the polymerization of the alkylcyanoacrylate monomers on the chain-end of PEG adapting the historical emulsion polymerization method [Lourenco et al., 1996, Perrachia et al., 1997 a,b]. Other methods considered the synthesis of amphiphilic copolymers composed alkyl cyanoacrylate and PEG that were then converted into PEGcoated nanoparticles by nanoprecipitation [Choi et al., 1995, Peracchia et al., 1997, 1999]. The method based on the synthesis of the poly(hexadecyl cyanoacrylate-co-methoxy PEG-hexadecyl cyanoacrylate [P[HDCA-co-MePEGCA) [Peracchia et al., 1997, 1999] was favored in many subsequent works [Stella et al., 2000, 2007, Nicolas et al., 2008, 2009, 2011, Le Droumadet et al., 2012]. Regardless of the approach, the PEGylation of the PACA-based nanoparticles had a significant incidence on the biodistribution [Perrachia et al., 1999, Gulyaev et al., 1999]. Consistently with general observations reported elsewhere (Blume and Cvec, 1990, Gref et al., 1994, Bazile et al., 1995), this second generation of nanoparticles appeared "stealth" to the immune system. After intravenous administration, they remained for a long period of time in the blood circulation escaping rapid uptake by macrophages at the early time of the pharmacokinetics [Peracchia et al., 1999]. More importantly, the obtained "stealth" nanoparticles accumulated more in diseased tissues where they were able to deliver larger amounts of drugs compared with an administration of free drugs or of drugs associated with non-stealth nanoparticles (Brigger et al., 2002, 2004, Calvo et al., 2002). It was suggested that the mechanism used by "stealth" nanoparticles to target more drug molecules in diseased tissues was based on the enhanced permeability and retention (EPR) effect that was described in the mid-1980s for the delivery of macromolecular therapeutics to tumors [Matsumura and Maeda, 1986, Maeda, 2001]. Since then, this mode of drug targeting has been widely explored to improve drug delivery in solid tumors. The EPR effect is heterogenous between tumors and the success of drug targeting strategies based on the EPR effect greatly depends on the tumor physiopathology and patients 
[Maeda, 2015]. Strategies are currently investigated to normalize the efficiency of EPR-mediated drug targeting using PACA-based nanotechnologies working together with the action of a physical stimuli including the activity of ultrasounds [Theek et al., 2016, Ojha et al., 2017, Snipstab et al., 2017]. Beside the important role of the EPR effect allowing nanomedicines to reach the diseased tissue, success of treatments is pending to the delivery of the antitumoral drugs to target cells [Brigger et al., 2004, Fang et al., 2011, Duncan and Richardson, 2012, Schroeder et al., 2012, Lammer et al., 2012, Park, 2013, Maeda, 2015, Nakamura et al., 2016].

Biodistribution studies of PEGylated PACA nanoaprticles performed on healthy animals revealed an interesting retention of these nanoparticles in the brain that was not observed considering their nonPEGylated counterpart [Gulyaev et al. 1999, Calvo et al. 2001b, Ambruosi et al., 2005, Wohlfart et al. 2012]. This result paved the way of a new area of research developing treatments of central nervous system disorders including neurodegenerative diseases assuming that PEGylated PACA nanoparticles can help drugs to go across the blood brain barrier (BBB) [Brigger et al., 2002, Calvo et al. 2001a,b, Kreuter et al., 2001]. Andrieux et al. 2009a,b, Brambilla et al., 2011, Wohlfart et al. 2012, Alyautdin et al., 2014, Kreuter, 2014, Gaudin et al. 2015, Saralva et al., 2016, Zhou et al., 2018] (See section 4.2.2.2.).

PEG is by far the most widely used hydrophilic polymer to produce so called "stealth" drug carriers [Lakkyreddy and Bazile, 2016, Suk et al., 2016, Aslund et al., 2017]. Few other synthetic polymers have been suggested but their use remains marginal so far [Amoozgar and Yeo, 2012]. In contrast, there is a growing interest using polysaccharides as an alternative to PEG [Lemarchand et al., 2004, Jin et al., 2011, Yu et al., 2014, Ibegbu et al., 2017, Juenet et al., 2018]. A method for the obtaining of stealth PACA nanoparticles using polysaccharides as coating materials was developed from a radical emulsion polymerization of alkylcyanoacrylate monomers [Chauvierre et al., 2003, Alhareth et al., 2012]. This was another method derived from the historical anionic emulsion polymerization method which provided with non-stealth polysaccharide-coated PACA nanoparticles. 
As discussed above, stealth nanoparticles can accumulate in pathological tissues were the permeability of blood vessels is increased [Lammer et al., 2012, Maeda, 2015, Ho et al., 2017]. This mode of drug targeting was named "passive" targeting because the nanoparticles have no specific mean to recognize their target site. They simply accumulate in diseased tissues thanks to favourable conditions given by the local physiopathology. To promote a targeting strategy based on specific interactions involving ligand-receptor like interactions between carriers and target cells, i.e. "active" targeting, targeting ligands were added on nanoparticle surfaces. Suitable ligands are generally chosen among molecules that interact specifically with overexpressed receptors found on target cell surface. Adding an active targeting functionality to the nanoparticles was assumed to enhance the efficacy of drug delivery to target cells compared with the delivery method based on passive targeting. The proof of concept has been established with PEGylated PACA nanoparticles decorated with folic acid taken as a specific ligand targeting cancer cells overexpressing the receptor of this small molecule [Stella et al., 2000, 2007]. Other drug targeting successes were then reported in vivo using monoclonal antibodies grafted on the surface of PACA nanoparticles but also on nanoparticles composed of other polymers [Aktas et al., 2005, Karatas et al., 2009, Ramon et al., 2013]. In general, the targeting strategy consists of enhancing drug delivery right to target cells. However, a ligand could also be used to promote interactions with endothelial cells of a specific tissue promoting the extravasation of the particles from the blood compartment to the target tissue. This was applied using an antibody against the transferrin receptor that is over expressed on the endothelium of the BBB [Qian et al., 2002]. The approach was found relevant improving the delivery of drugs such as peptides in the brain [Karatas et al., 2009, Paterson et al., 2016]. It is noteworthy that early attempts to develop active targeted PACA nanoparticles have failed because of the combination of stability problems and inadequate pharmacokinetics [Illum et al., 1984]. Both stealth carriers and strong anchorage of the targeting moiety are needed to improve the specificity of the drug delivery method towards target cells taking advantage of an active targeting method. For the success of the method, the carrier needs to reach the targeted cells after being distributed in the desired tissue (Dai et al., 2018). 
At present, the way to the success of the drug targeting concept with nanoparticles, and more generally with nanomedicines, is based on our know how to manipulate the biodistribution of nanoobjects. However, it is noteworthy that early studies having investigated pharmacokinetics and biodistributions of drugs delivered with PACA nanoparticles were carried out without having a deep knowledge on mechanisms that control the in vivo fate of intravenously injected nanoparticles. The results were very useful to draw strategies for the design of stealth nanoparticles preventing their immediate sequestration by the immune system after intravenous administration. They were also needed to implement the active targeting property to nanomedicines. Today, challenges remain to improve the performance of targeted nanomedicines taking advantages of the EPR effect and of a specific delivery to target cells [Nakamura et al., 2016, Dai et al., 2018, Rosenblum et al., 2018]. A better understanding of mechanisms that control the in vivo fate of nanomaterials, of the functioning of barriers between the site of administration and the site of activity and of the influence of the nanomaterial attributes on their drug delivery performances is now believed to benefit to the design of more efficient particles on a rationale basis [Bertrand and Leroux, 2012, Duncan and Richardson, 2012, Schroeder et al., 2012, Maeda, 2015, Anchordoquy et al., 2016, Nakamura et al., 2016, Hare et al., 2017].

\subsubsection{Enhancing drug delivery through physical biological barriers}

Biological barriers are impassable barriers for numerous APIs. Drugs may not diffuse across or/and are degraded. Nanoparticles were then expected to improve drug delivery across biological barriers including the gut epithelium, endothelia such as the BBB and the cell membrane of multidrug resistant cancer cells. As discussed below, several of the works having considered PACA nanoparticles have paved the way for further works on the oral delivery of peptides, and the design of innovative treatments for brain diseases and resistant cancers. 


\subsubsection{Oral delivery of peptides}

Taking a pill instead of multiple daily injections is the holy grail of hundred million of diabetic patients needing a systemic insulin-based treatment. In addition to patient comfort, oral insulin would provide a therapeutic advantage as the hormone will be routed directly to the liver via the portal vein after intestinal absorption mimicking the physiological pathway of the insulin secreted by the pancreas [Arbit and Kidron, 2018, Gedawy et al., 2018]. Efforts on the design of oral treatments of diabetes with insulin can be recorded up to the discovery of the hormone by Banting and Best in 1922 [Banting and Best, 1922, Fisher, 1923, Scott et al., 1932]. However, the task is extremely difficult because large peptides are generally destroyed by physiological food digestion pathways occurring in the gastro intestinal tract [Gedawy et al., 2018]. When they appeared, colloidal particles were rapidly considered as potential vehicle candidates to achieve oral delivery of peptide drugs assuming that they will insure a protection against degradation and may promote absorption of the peptide through the gut mucosa when a systemic activity is required [Vauthier et al. 1999]. Early experiments with the first biodegradable nanoparticles made of PACA have then paved the way to the tremendous subsequent works having considered polymer nanoparticles to this aim [Des Rieux et al. 2006, Damgé et al. 2007, Fonte et al. 2015, Lakkireddy et al., 2016, Lundquist and Artursson, 2016, Wong et al. 2017]. Opening the way, Maincent et al. have demonstrated an improvement of the oral bioavailability of vincamine, a low Mw API when it was formulated in PACA nanoparticles [Maincent et al., 1984, 1986]. Then, the transmucosal passage of PACA nanoparticles through the small intestine mucosa after oral gavage to rats was proven using electron microscopy [Aprahamiam et al., 1987]. This result was consistent with the primary assumption. Then, it was demonstrated that orally administered insulin-loaded PACA nanocapsules reduced the glycemia of diabetic rats [Damgé et al., 1988]. The results were promising, and numerous further works have later consolidated previously reported data [Lowe and Temple, 1994, Damgé et al., 2000, Pinto-Alphandary et al., 2000, Watnasirichaikul et al. 2000, Damgé et al. 2000]. Today, the challenge of the oral delivery of insulin remains a difficult subject. Many questions about the mechanism, the safety and effectiveness of delivery methods that uses nanotechnologies 
such as polymer nanoparticles are yet unanswered [Card and Magnuson, 2011, Fonte et al. 2015, Aguirre et al., 2016, Griffin et al., 2016, Lakkireddy et al., 2016, Lundquist and Artursson, 2016, Moraz et al., 2016, Gedawy et al., 2018]. In the meanwhile, the approach initiated by Patrick Couvreur and coworkers in 1988 [Damgé et al., 1988] on the oral delivery of insulin with PACA nanoparticles has also been extended to many other therapeutic peptides and the use of other types of polymer nanoparticles [Couvreur and Puisieux, 1993, Vranckx et al., 1996, Damgé et al., 1997, Couvreur and Vauthier, 2006, Fonte et al., 2015, Batista et al., 2018, Kafka et al., 2011]. The success of the approach raises debate. It seems utopian for some authors, but for others, the use of nanotechnologies to design active oral formulations of therapeutic peptides like insulin opens promising perspectives [Damgé et al., 2007, Des Rieux et al., 2006, Pridgen et al., 2015, Aguirre et al., 2016, Lakkireddy et al., 2016, Moroz et al., 2016, Leroux, 2017, Wong et al., 2017]. Within the last decade, works considering the development of oral formulations of peptides based on polymer nanoparticles were pursued including with PACA nanoparticles [Kafka et al., 2011]. Works also continue to fill gaps improving the understanding of mechanisms behind oral delivery of such fragile molecules using nanotechnologies [Beloqui et al. 2016, Griffin et al., 2016, Lundquist and Artursson, 2016, Lakkireddy and Bazile, this volume]. The bioavailability of oral insulin delivered by nanotechnologies is improved compared with free insulin but remains low [below 15-20\%] and the obtained activity can fluctuate comparing different works and diabetic models [See for instance Czuba et al., 2018]. Needs of insulin in treatments of diabetes currently covered by parenteral injections still cannot be fully replaced by oral dosage. Holding promise, preclinical programs developing oral formulations of insulin-based nanotechnologies including polymer nanoparticles are currently underway in several companies [Aguirre et al., 2016, Lakkireddy et al., 2016, Lakkireddy and Bazile this volume, Arbit and Kidron, 2017].

\subsubsection{Delivery of drugs to the brain}

The (BBB) is an unavoidable barrier to deliver drugs to treat brain diseases. It is a vital barrier that separates the brain tissue from the blood that circulates in the vascular compartment. Because of its highly selective permeability, the brain tissue is generally not accessible to drugs in normal conditions 
but even in pathologies in which the permeability of the BBB is increased such as Parkinson, Alzheimer diseases and stroke [Saraiva et al., 2016]. Different tactics have been proposed to assist drug delivery across the BBB thanks to progresses on the understanding of the biological structure and functioning of the BBB [Garcia-Garcia et al., 2005a, Paterson and Webster, 2016, Saraiva et al., 2016, Zhou et al., 2018]. This allows optimistic perspectives for the development of efficient treatments against major threats of the central nervous system. The use of nanoparticles is emerging as an effective and relatively non-invasive method with the other advantage of being applicable to a wide panel of API including the most innovative molecules, i.e. peptides, proteins, various types of nucleic acids (siRNA, miRNA, .....) [Andrieux and Couvreur 2009a, 2013, Kreuter, 2014, Saraiva et al., 2016, Zhou et al., 2018]. Early works having considered the use of colloidal carriers have started in the 1990s with micelles and liposomes [Garcia-Garcia et al., 2005a]. The potential of PACA nanoparticles was investigated concomitantly with the development of their stealth species. Whatever was the approach used to decorate the surface of PACA nanoparticle with PEG [i.e. formulating nanoparticles by nanoprecipitation of P[HDCA-co-MePEGCA] copolymer [Perracchia et al., 1997a,c], or by adsorption of polysorbate 80 on the surface of pre-synthetized PACA nanoparticles [Kreuter et al., 1995]], the obtained nanoparticles accumulated better in the brain of healthy animals and animal models of central nervous system diseases compared with their un-PEGylated counterparts [Calvo et al. 2001a,b, Perracchia et al. 1999, Kreuter et al. 1995, Andrieux and Couvreur 2009a, 2013, Andrieux et al., 2009b, Wohlfart et al., 2012, Kreuter 2014]. The mechanism behind the observed retention of the nanoparticles in the brain was deciphered thanks to efforts made on the development of an in vitro model of BBB in rats [Garcia-Garcia et al. 2005b] and of techniques allowing the analysis of proteins adsorbed on nanoparticles [Kim et al., 2007a]. The role of several apolipoproteins [Apo A-1, B and E] that adsorbed on the nanoparticle surface during opsonization by blood proteins appeared fundamental [Kreuter et al., 2002, Michaelis et al., 2006, Kim et al., 2007a, Kreuter 2014]. These adsorbed proteins were keys to initiate a receptor-mediated endocytosis of the nanoparticles with 
apolipoprotein receptors found on the BBB endothelium that then translocated the nanoparticles into the brain (Figure 2) [Kim et al., 2007b, Andrieux and Couvreur, 2013].

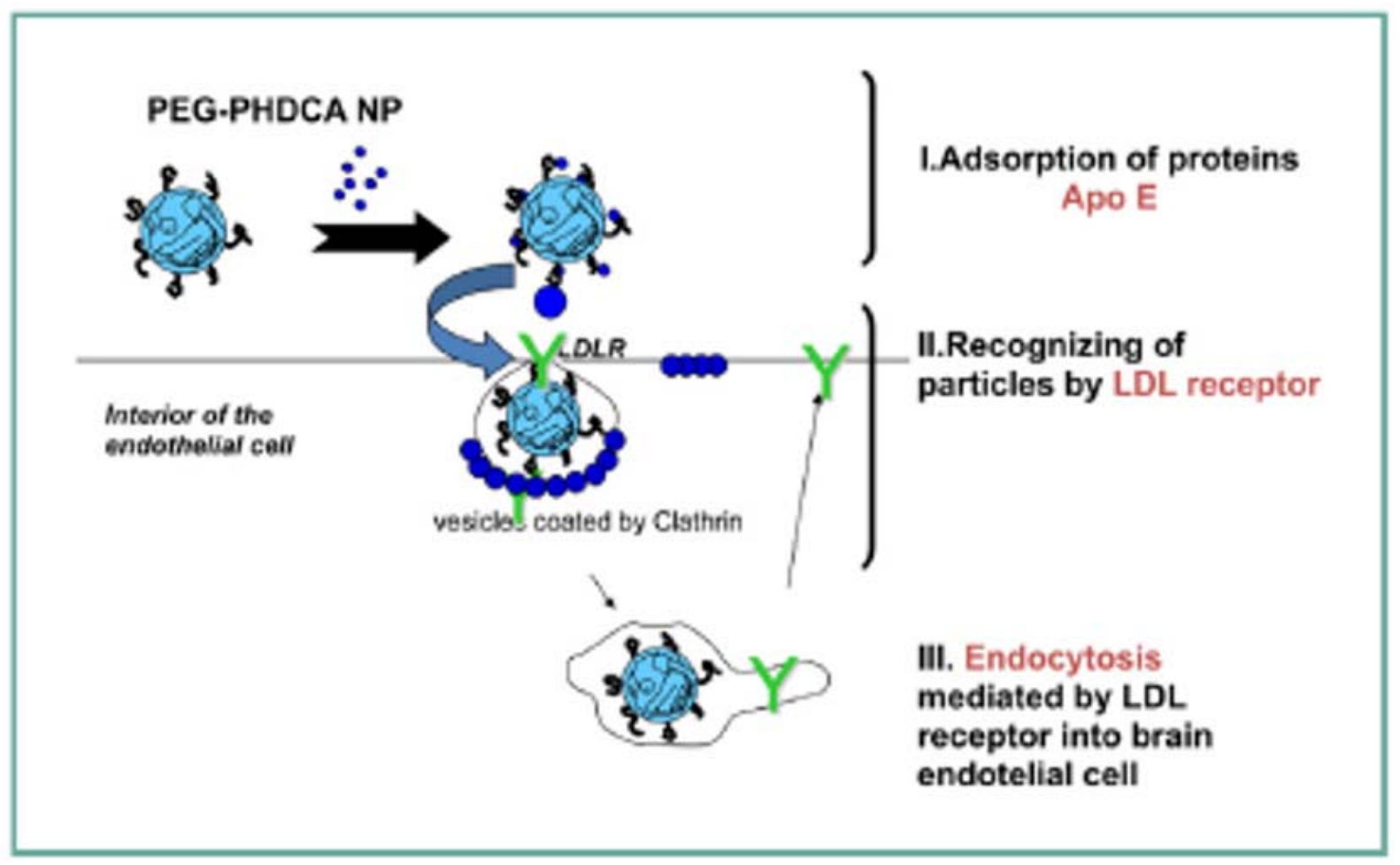

Figure 2: Mechanism suggested to explain the passage of P[HDCA-co-MePEGCA] nanoparticles across the blood brain barrier [BBB]. [I] A serum protein, apolipoprotein $E[A p o E]$ adsorbed on the surface of the nanoparticles. [II] The ApoE decorated nanoparticles are recognized by low density lipoprotein [LDL] receptors at the surface of the brain endothelial cells. [III] The nanoparticles penetrate into the endothelial cells and then are translocated across the BBB. [Reproduced with permission from Andrieux and Couvreur, 2013.

These nanoparticles acquired their targeting property from their opsonization by blood proteins. The elucidation of the mechanism behind the accumulation of the nanoparticles in the brain have paved the way to further drug targeting developments to the brain based on the use of apolipoproteins [Michaelis et al., 2006]. 
Another strategy explored by Patrick Couvreur and his coworkers was based on the targeting of drug loaded nanoparticles towards the receptor of the transferrin that is another receptor found in large amount on BBB capillaries which could trigger a receptor-mediated transcytosis pathway to the brain [Paterson and Webster, 2016]. This pathway was previously established with drugs coupled to a rat transferrin receptor monoclonal antibody, the OX26 monoclonal antibody [Qian et al., 2002]. In general, one antibody could transport one API molecule. Using nanoparticles, it was assumed that more drug molecules could be transported at once [Aktas et al., 2005]. The proof of concept was provided by grafting the OX26 monoclonal antibody on PEGylated chitosan nanoparticles transporting a peptide inhibitor of the enzyme Caspase 3 involved in ischemia processes [Karatas et al., 2009]. The application of the drug delivery concept has demonstrated remarkable neuroprotective activity of the inhibitory peptide while delivered with the targeted nanoparticles from an intravenous injection on a model mice of brain ischemia [Karatas et al., 2009]. The targeted nanoparticles were able to reach the brain tissue thanks to their translocation from the blood via the transferrin receptor of the BBB [Aktas et al., 2005]. Initially, the caspase 3 inhibitory peptide was only active if delivered by intracerebroventricular administration that is difficult to implement. The work of Karatas et al. paved the way for the development of brain disease treatments with biologically active peptides delivered to the brain with nanoparticles injected intravenously [Karatas et al., 2009]. Today this has become very important. Intravenous injections are easily accessible and treatments of central nervous system disorders by this route is highly anticipated. New molecule candidates for treatments are identified from the better understanding of biological processes behind diseases. Many are peptides that needs to be delivered into the brain. The use of polymer nanoparticles that opens interesting prospect to achieve brain delivery from an intravenous injection is then frequently explored to develop treatments for various disorders of the central nervous system including neurodegenerative diseases, i.e. Parkinson, Alzheimer, ischemia caused by strokes and brain cancers, i.e. glioblastoma...[Andrieux et al., 2009, Andrieux and Couvreur 2009, 2013, Brambilla et al., 2011, Saraiva et al., 2016, Alyautdin et al., 2014]. 


\subsubsection{Bypassing the cell membrane of multidrug resistant cancer cells}

Drug resistance is a major cause of failure of chemotherapies. By the end of the 1980s' early 1990s', assumptions on mechanisms behind tumor resistance to chemotherapies applied in cancer treatments were emerging. Biologists explained the loss of drug sensitivity of cells by an increase of the number of copies of efflux pumps occurring as transmembrane glycoproteins on the membrane of resistant cells [Gottesman and Pastan, 1993, Germann et al., 1993]. This mechanism, called mdr-1 for multidrug resistance \# 1, was deciphered later revealing that cells acquired the resistance phenotype by overexpressing the gene coding for a glycoprotein that was named Pgp. Now, it is known that this mechanism is part of a cell detoxification process, but the overexpression of the Pgp considerably reduces efficacy of chemotherapies hampering drugs to penetrate inside resistant cells [Gottesman et al., 2002, Gottesman and Pastan 2015, Housman et al., 2014]. As soon as resistance to chemotherapy was assumed to be associated with a delivery problem of the API inside cells, different strategies including the use of drug carriers were explored to enhance the penetration of the drug in the cells. The already described doxorubicin-loaded PACA nanoparticles (Couvreur et al., 1982, Chiannilkulchai et al., 1989) were on the first line of the polymer nanoparticles to be tested for their ability to deliver an anticancer drug to resistant cells. Works has started considering a mdr-1 cancer resistant murine cell line evaluating the cytotoxicity of various formulations of the doxorubicin-loaded PACA nanoparticles in cell cultures [Treupel et al., 1991, Cuvier et al., 1992, Bennis et al., 1994, Nemati et al., 1994, 1996, Colin de Verdière et al., 1997]. Results were immediately impressive as sensitivity to doxorubicin of resistant cell lines treated with doxorubicin-loaded PACA nanoparticles could be raised to the same level than that of the corresponding sensitive cancer cell line. The observation was repeated considering different resistant cancer cell lines strengthening results obtained in the initial work. [Treupel et al., 1991, Cuvier et al., 1992, Bennis et al., 1994, Nemati et al., 1994]. Intriguingly, the effect was only observed with PACA nanoparticles while other types of polymer nanoparticles including nanoparticles made of alginate and PLGA were ineffective to increase drug sensitivity of the 
resistant cells. This was explained later by the unique mechanism of drug delivery through the cell membrane given by the PACA nanoparticles [Nemati et al., 1996, Colin de Verdière, 1997] (Figure 3). The very interesting efficiency shown by PACA nanoparticles to deliver anticancer drugs to resistant cancer murine cells was also observed considering resistant cancer human cells [Barraud et al., 2002, 2005] paving the way to the development of a treatment of human hepatocellular carcinoma [HCC] [EU/3/04/229 EUDRACT 2006-004088-77, NCT01655693] (see section 5).

A)

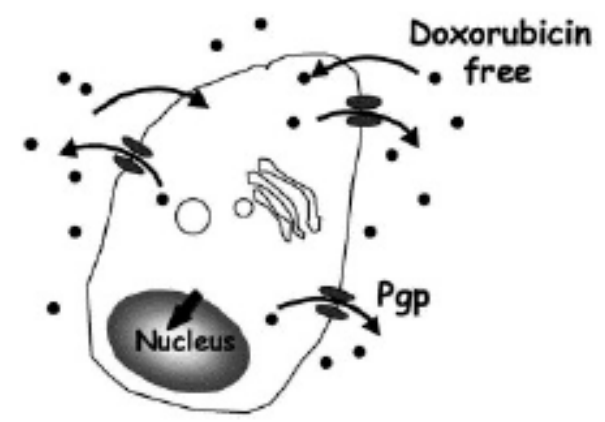

B)

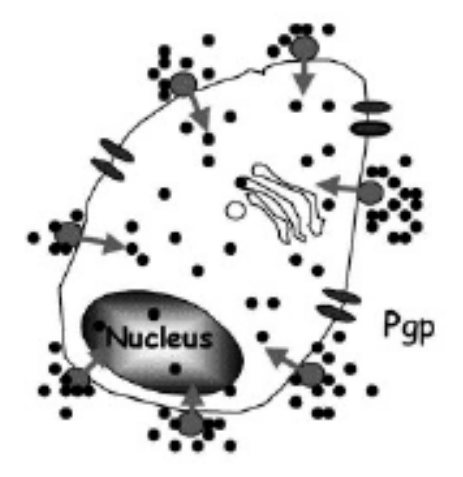

C)

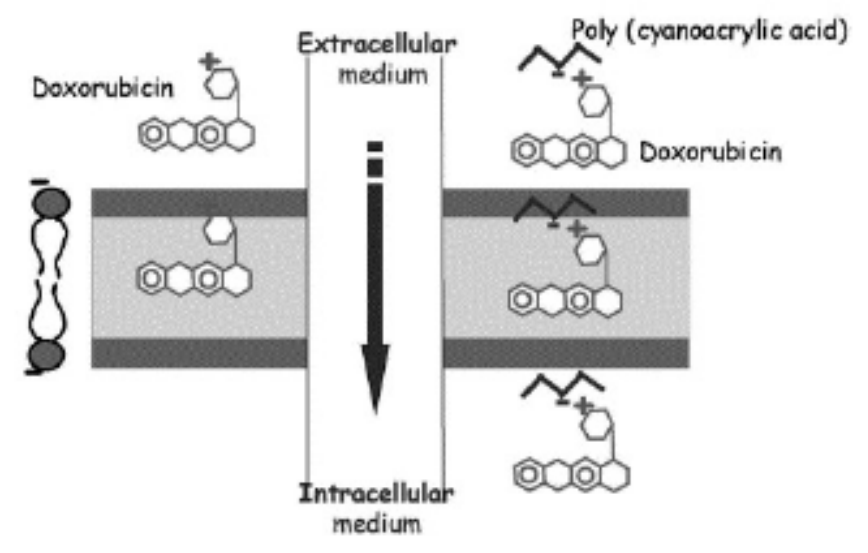

Figure 3: Delivery of doxorubicin, a chemotherapeutics agent, to mdr1 resistant cancer cells expressing the Pgp efflux pump. [A] Delivery of the free drug: The free doxorubicin is pumped out of the cell by 
the Pgp while going across the cell membrane (left part of $[C]$ ). The Pgp hampers the free docorubicin to enter in the cells. [B] Delivery of doxorubicin with PACA-based nanoparticles: Doxorubicin is released near the cell membrane while PACA nanoparticles are degraded. Doxorubicin and the main degradation product of the nanoparticles, the poly(cyanoacrylic acid), form ion pairs which can diffuse through the cell membrane without being recognized by the Pgp (right part of [C]). Doxorubicin can reach the interior of the cells [Reproduced with permission from Brigger et al., 2012]

\subsection{Exploring potential of polymer nanoparticles to treat diseases: the way to the birth of nanomedicines}

Pharmaceutical formulations that incorporate nanocarriers were expected to produce a favorable clinical outcome of treatments offered to patients with an increase of their quality of life. Along the years, polymer nanoparticles were shown to be suitable carriers to manipulate the pharmacokinetic and biodistribution of drugs to improve chemotherapies treating severe infections and cancers [Couvreur et al., 1990, Pinto-Alphandary et al., 2000, Murthy and Reddy, 2006, Abed et al., 2015, Friberg and Nyström 2016, Sobot et al., 2016]. It has also been established that they can help medications pass through difficult biological barriers. This raises tremendous hopes for the development of treatments of diseases of the central nervous system that require delivery of APIs in the brain [Andrieux and Couvreur, 2013, Kreuter, 2014, Savaira et al., 2016, Zhou et al., 2018]. Another area where polymer nanoparticles are presently believed to bring benefits for patients in the future include the design of treatments based on oral administration of therapeutic peptides. Currently, researches are very active on treatments of diabetes requiring insulin [Pridgen et al., 2015, Aguirre et al., 2016, Lakkireddy et al., 2016, Moroz et al., 2016, Wong et al., 2017] but other metabolic diseases are interested by the outcome of these works. Results from these works also interest treatments of many other diseases for which the number of peptides in the therapeutic arsenal is increasing 
[Fosgerau and Hoffmann, 2015, Lau and Dunn, 2018]. We must admit that the number of approved formulations of medicines based on nanotechnologies remains low [Park, 2013, Venditto and Szoka, 2013, Salkatar et al., 2016a, Lee Ventola, 2017, Lakkireddy and Bazile, This volume]. However, a significant way to clinical translation have been achieved since the initial works of the pioneers and considering that the task has been found extremely complex. Along the way, studies that have explored the potential of PACA nanoparticles to design treatments for patients were at the forefront of those dealing with biodegradable nanoparticles [Couvreur, 1984, Kreuter, 1985, 2005, Couvreur, 1988, Couvreur and Vauthier, 1991, Vauthier et al., 2003a,b, Murthy and Reddy, 2006, Kreuter, 2007, Vauthier et al., 2007, Nicolas and Couvreur, 2009, Nicolas and Vauthier, 2011, Yordanov, 2012, Alonso and Couvreur, 2012] even if their interest was questioned from time to time [Graf et al., 2009, Merkle, 2015]. They were used to demonstrate proofs of concept considering "old" APIs. Over the years, biological mechanisms behind pathologies have been deciphered leading to the introduction of new therapeutic strategies based on molecules which require targeted delivery methods to be active in vivo. This was the case of very innovative treatments against cancer based on the silencing of the expression of oncogenes using nucleic acid fragments as APIs [Juliano, 2016]. The approach emerged from the end of the 1970's after the discovery and understanding mechanisms of action of antisens oligodeoxynucleotides (AsODN) [Stephenson and Zamecnik, 1978], microRNA or microDNA, [Lee et al., 1993, Christopher et al., 2018] and small interfering RNA (siRNA) [Fire et al., 1998]. PACA nanoparticles were among the first drug carriers tested to explore proofs of concept of cancer treatments using these very new APIs. They were first explored in the case of the delivery of AsODN [Chavany et al., 1992, Schwab et al., 1994] and then considered as delivery system to administer siRNA demonstrating the feasibility of intravenous treatments [Toub et al., 2005, De Martimprey et al., 2009, Ramon et al., 2013]. Beside exploring treatments based on the delivery of nucleic acids, the potential of PACA nanoparticles has been investigated for treatment based on oral administration of peptides to treat metabolic diseases with diabetes at the forefront (see section 4.2.2.1.) and of treatments based on the administration of poorly soluble anticancer and anti-infectious molecules [Monza da Silveira et al., 
1998, Layre et al., 2006] and of poorly diffusible compounds [Fattal et al., 1989, Hillaireau et al., 2006, 2007]. Many of these works have given proofs of concepts of delivery methods based on the use of polymer nanoparticles. These works inspire current researches on treatments based on the use of nanotechnologies holding promise to treat resistant cancers [Friberg and Nyström, 2016, Li et al., 2017, Nicolas and Couvreur, 2017, Sobot et al., 2017], intracellular infections [Abed and Couveur, 2014, Jiang et al., 2018] metabolic diseases [Lakkireddy and Bazile, 2016, Wong et al., 2017] and diseases of the central nervous system [Andrieux and Couvreur, 2013, Kreuter, 2014, Savaira et al., 2016].

Considered as simple drug carrier in most works, nanoparticles are presently designed to achieve several functions [Mura et al., 2013, Mura and Couvreur 2016a, Lamch et al., 2018, Hu et al., 2018]. Their potential to deliver drugs at a specific site in the body under a better control of the biodistribution was extended with a timely component to achieve spacio-temporal controlled delivery at the site of the activity [Mura et al., 2013, Hassanzadeh et al., 2018]. Thus, by adding a corresponding functionality, a precise control of the release of the drug can be triggered by the mean of a stimulus that can be a change in $\mathrm{pH}$, of oxydo-reduction conditions, of temperature or by a specific enzymatic activity occurring at the site where the release of the drug is desired [Mura et al., 2013, El-Sawy et al., 2018]. The release of the drug can also be triggered through the action of an external stimulus [Theek et al., 2016, Snipstap et al., 2017]. Additionally, to the initial drug delivery function, diagnostic functionalities were also added [Reddy and Couvreur, 2011, Mura and Couvreur, 2012, 2016a, Hassanzadeh et al., 2018]. When both drug delivery and diagnostic functionalities are implemented in a single nanoparticle, it then becomes a nanotheranostic particle being able to assist diagnostic and deliver treatment at the same time. The integration of several functionalities in a single nanoparticle can be achieved using methods of fabrication based on the self-assembly of polymers bearing the different functions. The method which tends to generalize was recently implemented on PACA-based nanoparticles developing a customizable multifunctional plateform [Nicolas et al., 2008, 2013, Le Droumadet et al., 2012]. 
From the very few nanotechnologies born in the 1970's early 1980s', the field has expanded tremendously and became a separate field of nanotechnologies dedicated to health care named nanomedicine in the 1990s' [see Krukemeyer et al., 2015]. From the simple idea of improving drug delivery to target sites has emerged an area in which the use of nanotechnology is being currently considered in a much wider range of applications, including the combination of treatment and diagnosis with high promise for the development of personalized medicine [Mura and Couvreur, 2012, 2016b, Ryu et al., 2014, Fornaguera and Garcia-Celma, 2017]. From his work, Patrick Couvreur has contributed to progress in the understanding of the design of nanoparticular drug carriers increasing precision of their function to suit exigencies of a treatment with a given API. An important part of his contribution has followed his historical work exploring the potential of PACA nanoparticles for the development of treatments hindered by drug delivery issues. It is impossible not to underline that the visionary work of Patrick Couvreur exploring new treatments developing nanocarriers as the "nanopills" have also considered nanoparticles composed of different polymers including poly(lactic acid) (PLA) [Verrecchia et al., 1993, Desgouilles et al., 2003] and poly(E-caprolactone) (PCL) [Lemarchand et al., 2003], nanogels [Rajaonarivony et al., 1993, Gref et al., 2006] and other types of nanotechnologies such as liposomes [Weingarten et al., 1985, Laham et al., 1988, Ropert et al., 1992, 1993a,b, Fattal et al., 2004], lipid based nanotechnologies (squalenoylated nanoparticles) [Couvreur et al., 2006, Couvreur 2009, Desmaële et al., 2012, Feng et al., 2017] and porous metal-organic framework nanomaterials [Horjacada et al., 2010, 2012, Simon-Yarza et al., 2017]. Thanks to the early pioneers who brought many other researchers in their wake and laid the foundations of the field, nanomedicines have now reached a sufficient maturity accelerating their entry into phases of clinical development. There are still challenges to lift but a new era has begun [see section 5]. 


\section{On the way to clinical translation}

The number of projects including drug delivery systems based on nanotechnologies entering in clinical trials increases over the past decade indicating that clinical translation of nanomedicines is on the way [Svenson, 2014, Wicki et al., 2015, Anselmo and Mitragotri, 2016, Bodo et al., 2016, Luque-Michel et al., 2016, Bulbake et al., 2017, Caster et al., 2016, Lee Ventola, 2017, Lee et al., 2017, Li et al., 2017, Cicha et al., 2018]. Time was needed to reach the required level of maturity. Efforts in many directions have been made to fill gaps from the early academic works and to translate the acquired knowledge into viable clinical projects [Baldrick, 2000, Desai, 2012, Duncan, 2015, Kamaly et al., 2012, Lammers et al., 2012, Venditto and Szoka, 2013, Lakkireddy and Bazile, This volume]. Everything was new, and even terminologies needed to be defined [Duncan and Gaspar, 2011, Merkle, 2015, Salkatar et al., 2016b]. Nanomedicines are very different from all previously developed medicines from chemical molecules from which regulatory authorities and big pharmas were familiar. They are complex systems which in vivo fate and activity can be manipulated from their given properties. Thus, time was needed to evaluate and establish specific guidelines for their clinical development. Time was required to identify key attributes and set corresponding methodologies to achieve safety and efficacy of this new types of medications. All aspects have not been cleared yet, but frameworks and guidelines were suggested facilitating current initiations of clinical projects. A number of remaining challenges were identified and discussed [Lammers et al., 2012, Clogston and Patri, 2013, Couvreur, 2013, Tinkle et al., 2013, Dusinska et al., 2015, Gaudin et al., 2015, Ilinskaya and Dobrovolskaia, 2016, Dobrovolskaia et al., 2016, Satalkar et al., 2016a, Hare et al., 2017, Cicha et al., 2018, Gao and Lowry, 2018, Lakkireddy and Bazile, This volume, Su et al., 2018]. Several pitfalls have been identified from projects that have failed in their clinical translation [Lammers et al., 2012]. Other factors have delayed clinical developments. Funds were cruelly missing until governments and funding agencies have given priority for the development of nanomedicines at the beginning of the 2000s. Moreover, considered as "scientific curiosity" by big pharmas, clinical projects could only be supported by start-up companies 
based on venture capital. In this context, very few initiatives have been taken before 2000 [Kreuter, 2007, Barrenholz, 2012, Interview of P. Couvreur by Stanwix, 2014, Merkle, 2015]. So far, most of the clinical projects were conducted on liposomes [Alonso and Couvreur 2012, Caster et al., 2016, Bulbake et al., 2017, Lee Ventola 2017, Lee et al., 2017, Lakkireddy and Bazile, This volume]. In parallel of the early clinical translation of liposomes, Patrick Couvreur started a clinical trial sponsored by a Belgium pharmaceutical company, Sopar, evaluating clinical potential of intravenously injected doxorubicinloaded poly(iso hexyl-cyanoacrylate) (dox-PIHCA) nanoparticles [Kattan, et al., 1992]. This was a phase I clinical trial having involved 21 patients with various solid tumors. Several key results on the safety and pharmacokinetics of the drug associated with nanoparticles were provided for the first time in human. The treatment with nanoparticles administered intravenously was generally well tolerated by the patients. The unexpected reversible side effects observed in some patients were like those reported from clinical studies carried out with liposomes. Today, we know that these side effects were the consequence of a complement activation-related pseudoallergy [CARPA] reaction that may occur with some patients following injections of nanomedicines and were later understood from the work of Szebeni and his coworkers [Szebeni et al., 1999, 2000, Szebeni, 2014]. The reaction can be managed but it was responsible for a few dramatic accidents in the course of several early clinical trials conducted on nanomedicines [Szebeni et al., 1999, 2000, Barrenholz, 2012, Soma et al.,2012, Szebeni 2014, Merle et al., 2017, Moghimi, 2018]. Regarding the pharmacological activity of the polymer nanoparticle formulation of doxorubicin, this clinical study has revealed a superior therapeutic index of doxorubicin administered with the nanoparticles compared to that of the free drug with no cardiotoxicity. Besides, one of the conclusions drawn from this work pointed out a potential activity of the doxorubicin-nanoparticles on multidrug resistant cancer. This was an important conclusion that served later for the design of a new clinical trial.

Despite promising results, the clinical evaluation of the dox-PIHCA nanoparticles was not continued due to major changes in the organization of the sponsors' company. Search for sponsors to support clinical translation of the first nanomedicines was tedious for pioneers [Kreuter, 2007, Barrenholz, 
2012, Interview of P. Couvreur by Stanwix, 2014]. Clinical trials on dox-PIHCA nanoparticles have taken a new start after the startup named BioAlliance Pharma [changing its name to Onxeo in 2014] was founded by Dominique Costantini and Gilles Avenard in 1997 in Paris, France with the collaboration of Patrick Couvreur. The formulation of dox-PIHCA nanoparticles considered in the new clinical project was named doxorubicin Transdrug ${ }^{\circledR}$ or BA003 [Soma et al., 2012, Merle et al., 2017] [Later named Livatag $^{\circledR}$ ] and was proposed as a treatment of advanced HCC. This deadly drug resistant cancer of the liver remained without therapeutic option at the time of the start of the clinical trial in 2004 [EU/3/04/229 EUDRACT 2006-004088-77] [Keating and Santoro, 2009, Giglia et al., 2010, Cucchetti et al., 2017, Desai et al., 2017, Lu et al., 2018, Raoul et al., 2018]. This choice was consistent with the established ability of dox-PIHCA nanoparticles to overcome multidrug resistance of cancers [Kattan et al., 1992, Colin de Verdière et al., 1997]. This phase I trial involved 20 patients highlighting a significant survival benefit for several patients treated with doxorubicin Transdrug $^{\circledR}$ even after a single administration [Soma et al., 2012, Merle et al., 2017]. A phase II clinical trial was initiated in December 2006 right after the completion of the phase I clinical trial in July 2006 [Merle et al., 2017]. It was aimed to compare the efficacy of doxorubicin Transdrug ${ }^{\circledR}$ with the best standard of care of this moment which was a palliative treatment based on trans-arterial chemoembolization. The trial was terminated prematurely in July 2008 because 3 out of the 17 patients treated with doxorubicin Transdrug ${ }^{\circledR}$ experienced fatal acute respiratory distress associated with CARPA, the type of dramatic side effect also reported with some patients treated with other treatments based on nanotechnologies such as liposomes [Szebeni et al., 1999, Barrenholz, 2012]. To pursue clinical evaluation of the nanoparticles, modalities for their administration have been revised. While administered to patients through the hepatic intra-arterial route, it was decided to change for a slow infusion by the intravenous route consistently with results of a report suggesting that the incidence of the CARPA reaction could be attenuated using this mode of administration [Szebeni et al., 2000]. The new clinical trial named RELIVE [NCT01655693] was started in 2012 including a phase II-III. Patients of the control group have received an active treatment including anticancer agents [such as gemcitabine, oxaliplatin] and sorafenib, a new 
treatment based on multikinase inhibitors approved for HCC in 2007 [Onxeo, 11 septembre 2017, Kearting and Sanoro, 2009, Cuccetti et al., 2017, Desai et al., 2017, Raoul et al., 2018]. This was a major change compared with previous clinical trials in which patients of the control arm received a palliative treatment as no active treatments on $\mathrm{HCC}$ was available at these times. Having been granted a fast tract from the FDA in May 2014 [Onxeo, 19 May 2014], we are now past the primary completion date of this clinical trial that was set in September 2017. So far, few results were presented in congresses [Merle et al., 2017b, Merle et al., 2015] and primary conclusions were given by the sponsor [Onxeo, 11 and 17 Sept 2017]. In numbers, this randomized multicenter clinical trial has recruited a total of 398 patients from 11 countries, 264 patients were treated with Livatag ${ }^{\circledR}$ after having been treated with sorafenib [Merle et al., 2017b]. Regarding safety aspects of the treatment, no pulmonary toxicity was reported in patients treated with Livatag [Merle et al., 2015, Onxeo 11 sept 2017]. The change of administration modality in favor of a slow infusion by the intravenous route was paid off for the safety. It is also easier to implement in clinical practice compared to the difficult to perform intra-hepatic arterial route used in the previous phase I and II clinical trials [Soma et al., 2014 Merle et al., 2017a]. The primary end point of the phase III trial was to obtain an improved survival in the groups of patients treated with Livatag ${ }^{\circledR}$ compared with patients of the control group. First conclusions based on the primary end point of this clinical trial were disappointed as the tested formulation did not add survival benefit for patients compared to best standard of care that have included for the first time an active treatment of HCC. Compared with another active treatments, the Dox-PIHCA nanoparticles composing Livatag $^{\circledR}$ were as efficient as these treatments in terms of survival improvement. Without additional benefit for patients, Livatag ${ }^{\circledR}$ has probably no chance to get an approval as a treatment of HCC yet. Final conclusions on this clinical trial phase III are expected in January 2019 [NCT01655693].

Another clinical trial was achieved on PACA nanoparticles in China during the years 2000 [Sichua Food and Drug Administration 1999-266]. This was a phase II that have evaluated mitoxanthrone (dihydroxyanthracenedione)-loaded poly(isobutyl cyanoacrylate) (DHAD-PIBCA) nanoparticles in a treatment of HCC using an intravenous slow injection (at least $15 \mathrm{~min}$ ) [Zhou et al., 2009]. It has 
included 108 patients. This clinical study has also demonstrated the feasibility of an intravenous administration of PACA nanoparticles to human. A benefit for the patients in terms of survival was reported compared with the control arm including patients who received injections of the free drug. Although promising for patients with unresected HCC, no record for further clinical trial or publication could be found in the recent literature suggesting that the work was not pursued.

It is unclear yet whether one nanoparticle composed of PACA will be approved in the near future for a therapeutic use in human clinic. Despite all efforts, a very long delay was needed to complete a clinical trial phase III that was the most advanced clinical phase completed evaluating nanoparticles made of a synthetic polymer so far. In the mean while competing treatments were approved to help patients diagnosed with HCC [Desai et al., 2017, Raul et al., 2018] that presently hamper subsequent development of PACA nanoparticles for this application. Nevertheless, these clinical developments were among the first carried out on such nanomedicines. They have demonstrated the feasibility of the administration in human by a systemic route and have highlighted issued linked with the clinical development of such pharmaceutics with contributions to find solutions to bypass bottlenecks found on the way. Experiences and knowledge acquired from these clinical trials will profit to further projects if new opportunities will arise in the future.

\section{Overlook on current ongoing works on PACA nanoparticles}

There is apparently no ongoing clinical trial considering PACA-based nanoparticles, but research remains active. Following the way opened by pioneer works, their development as drug carriers is pursued. For instance, PACA-based nanoparticles are currently considered as drug carriers in treatment of different cancers [Cabeza et al., 2015, Snipstab et al., 2017, Fusser et al., 2018], cardiovascular diseases [Zhao et al., 2011, Juenet et al., 2017, Matuszac et al., 2016, 2018,] and brain diseases [Hu et al., 2017, Carradori et al., 2018]. Their potential is explored to promote drug release in tumors thanks to the application of an ultrasound-mediated delivery approach [Theek et al., 2016, 
Snipstab et al., 2017]. Few works considering their use in cancer therapies were related to preclinical and clinical developments [Sulheim et al., 2017, Zandanel et al., 2018]. Taking advantage of the Intrinsic antiparasitic activity of PACA-based nanoparticles is evaluated in another project. The nanoparticles are incorporated in hydrogels to enhance the mucosal antiparasitic barrier efficacy of the formulation designed to prevent infections at the door of entry of parasites [Pradine et al., 2015a,b, Malli et al., 2018]. Besides, progresses have been made in the development of the multifunctional PACA-based drug delivery platform developed at the end of the 2000's. It can be customized to achieve various drug targeting challenges to treat cancer and neurodegenerative diseases [Le Droumadet et al., 2012, Carradori et al., 2018]. It can incorporate quantum dots as fluorescent tags giving an optical imaging device that can be used to follow the nanoparticles in cells and in vivo [Nicolas et al., 2011]. A single nanoparticle can be labeled with two types of quantum dots giving a tool for multiplex detection. The obtained fluorescent nanoparticles can incorporate other functionalities opening the way to the synthesis of theranostic PACA-based nanoparticles [Nicolas et al., 2008, Le Droumadet et al., 2012]. This plateform which is easily customizable is now ready for further developments.

From the tremendous amount of works done on PACA nanoparticles, nanoparticles with different properties that influence their in vivo fate were obtained. Thanks to the robustness of corresponding methods of preparation, collections of spherical nanoparticles with reproducible surface characteristics were prepared and used in different fundamental studies that aimed to elucidate the influence of nanoparticle attributes on their in vivo fate, their interactions with biological molecules and cells [See for instance Lira et al., 2011 Alhareth et al., 2012, Coty et al., 2017, Sulheim et al., 2016, 2017, Baghirov et al., 2017]. These collections of nanoparticles provide tools to evaluate the performance of new characterization methods to investigate nanomaterial surface characteristics [Coty et al., 2018 a, b]. Recently, the feasibility of the obtaining of non-spherical PACA-based nanoparticles was achieved [Palazzo et al., 2017]. The shape is now another attribute of the nanoparticles that can be included in works that aim to understand better the relationship between nanoparticle attributes and biological responses hence the performance of nanomedicines according 
to their given attriutes. The need for such fundamental studies is clearly expressed in the literature to progress towards more clinical developments of nanomedicines [Moghimi et al., 2011, Duncan and Richardson, 2012, Dobrovolskaia et al., 2016, Hare et al., 2017, Shi et al., 2017]. The challenge is to enable the design of the next generation of nanomedicines that is expected to be done on a more rational basis eventually implementing multiple and customized functionalities. With the work that has began and the experience gained studying and developing PACA nanoparticles, it can be expected that these nanoparticles can further help in this challenge.

\section{Conclusion}

The first biodegradable polymer nanoparticles that were created four decades ago resulted from the polymerization of an alkylcyanoacrylate monomer contained in a surgical glue. Thanks to their remarkable adaptability in the sense that their properties could be tuned along needs, these polymer nanoparticles became keys to establish proofs of concepts deciphering a wide range of drug delivery challenges. With each new leap in pharmaceutical knowledge, a highly passionate and visionary leader has been able to give the necessary impetus to the work necessitated for their refinement, their adaptation to the targeted applications. This was Patrick Couvreur, the "Father" of the first PACA nanoparticles who, with few other pioneers, have paved the way to the birth of nanomedicines at the beginning of the journey when they decided to explore breakthrough technologies assumed to improve drug delivery methods. The development of original concepts in drug delivery, such as drug targeting, represented a huge gap compared to traditional drug delivery methods. It requires a multidisciplinary work involving many disciplines suh as polymer chemistry, physics, physicochemistry, biology, physiology, pharmacokinetics, and more generally pharmaceutical sciences and medicines. Through his creativity and enthusiasm, Patrick Couvreur has explored many facets of hurdles hindering efficacy of treatments related to drug delivery problems thanks to the help of PACA based nanoparticles. Results he has obtained inspired many other researchers and his more recent contributions have paved the way to the next generations of nanomedicines which promise an 
improved design to achieve a better control of their functionalities. Revolution in drug delivery methods is awaited to design better treatments of severe diseases and to implement novel therapeutic strategies using new drugs, with the final aim of improving the quality of life of patients. Challenges remain to be overcome. At present, among different emerging solutions, nanomedicines continue to provide promising options for this revolution although the task is complex and requires the mobilization of further efforts in research oriented towards clinical perspectives.

\section{Acknowledgments}

The author addresses her warm thanks to Gilles Ponchel for helpful discussions and critical readings of several parts of the manuscript during preparation. Thanks to Elias Fattal, the guest editor of this special issues, for his invitation to write a paper on the honor of Patrick Couvreur focused on the works done on PACA nanoparticles. The author has been a close coworker of Patrick Couvreur from 1987 to about 2003 while strong collaborations has continued since then. Thank you Patrick for having shared explorations of the potential of polymer nanoparticles to improve drug delivery performances. Thank you for your friendship, enthusiasm and for all the inspiring ideas shared to advance in the knowledge to improve the design of those nanoparticles.

\section{Potential Conflicts of interest}

The authors have been a close coworker of the researcher to whom this paper is dedicated.

\section{References}

Abed N, Couvreur P. Nanocarriers for antibiotics: a promising solution to treat intracellular bacterial infections. Int J Antimicrob Agents. 2014;43(6):485-496. DOI: 10.1016/j.ijantimicag.2014.02.009

Abed N, Saïd-Hassane F, Zouhiri F, et al. An efficient system for intracellular delivery of beta-lactam antibiotics to overcome bacterial resistance. Sci Rep. 2015;5:13500. DOI:10.1038/srep13500.

Agrawal U, Gupta M, Jadon RS, et al. Multifunctional nanomedicines: potentials and prospects. Drug Deliv Transl Res 2013;3(5):479-497. 
Aguirre TA, Teijeiro-Osorio D, Rosa M, et al. Current status of selected oral peptide technologies in advanced preclinical development and in clinical trials. Adv Drug Deliv Rev. 2016;106(Pt B):223-241. DOI:10.1016/j.addr.2016.02.004.

Ahmad Z, Sharma S, Khuller GK. Inhalable alginate nanoparticles as antitubercular drug carriers against experimental tuberculosis. Int J Antimicrob Agents. 2005;26(4):298-303. Erratum in: Int J Antimicrob Agents. 2010;36(2):195.

Aktaş $\mathrm{Y}$, Yemisci $\mathrm{M}$, Andrieux K, et al. Development and brain delivery of chitosan-PEG nanoparticles functionalized with the monoclonal antibody OX26. Bioconjug Chem. 2005;16(6):1503-1511.

Alhareth K, Vauthier C, Bourasset F, et al. Pharmacokinetics and tissue biodistribution in rats of doxorubicin loaded Poly(isobutylcyanoacrylate) nanoparticles prepared by redox radical emulsion polymerization, Eur J Pharm Biopharm. 2012;81(2):453-457. DOI:10.1016/j.ejpb.2012.03.009

Al Khouri-Falhou N, Roblot-Treupel L, Fessi H, et al. Development of a new process for the manufacture of polyisobutylcyanoacrylate nanocapsules, Int J Pharm. 1986;28:125-132. Doi: 10.1016/ /03785173(86)90236-X

Alonso MJ, Couvreur P. Historical view of the design and development of nanocarriers overcoming biological barriers. In: Alonso MJ, Csaba NS, editors. Nanostructured biomaterials for overcoming barriers. Dorchester (UK): RSC Publishing; 2012.p. 3-36.

Alonso MJ, Csaba NS. Nanostructured biomaterials for overcoming barriers. Dorchester (UK): RSC Publishing; 2012.

Alyautdin R, Khalin I, Nafeeza MI, et al. Nanoscale drug delivery systems and the blood-brain barrier. Int J Nanomedicine. 2014;9:795-811. DOI:10.2147/IJN.S52236.

Ambruosi A, Yamamoto $\mathrm{H}$, Kreuter J. Body distribution of polysorbate-80 and doxorubicin-loaded [14C]poly(butyl cyanoacrylate) nanoparticles after i.v. administration in rats. J Drug Target. 2005;13(10):535-542.

Amoozgar Z, Yeo Y. Recent advances in stealth coating of nanoparticle drug delivery systems, Wiley Interdiscip Rev Nanomed Nanobiotechnol. 2012;4(2):219-233. doi: 10.1002/wnan.1157.

Anchordoquy TJ, Barenholz Y, Boraschi D, et al. Mechanisms and Barriers in Cancer Nanomedicine: Addressing Challenges, Looking for Solutions. ACS Nano. 2017;11(1):12-18. DOI:10.1021/acsnano.6b08244.

Andrieux K, Garcia-Garcia E, Couvreur P. Colloidal carriers: a promising way to treat central nervous system diseases. J Neurosci 2009a;1(1), 17-34.

Andrieux K, Couvreur P. Polyalkylcyanoacrylate nanoparticles for delivery of drugs across the bloodbrain barrier. Wiley Interdiscip Rev Nanomed Nanobiotechnol. 2009b;1(5):463-474. DOI:10.1002/wnan.5

Andrieux K, Couvreur P. Nanomedicine as a promising approach for the treatment and diagnosis of brain diseases: The example of Alzheimer's disease. Ann. Pharm. Françaises. $2013 ; 71(4): 225-233$. DOI: 10.1016/j.pharma.2013.04.0012013

Anselmo AC, Mitragotri S. Nanoparticles in the clinic. Bioeng Transl Med. 2016;1(1):10-29. doi: 10.1002/btm2.10003. 
Anselmo AC, Gokarn Y, Mitragotri S. Non-invasive delivery strategies for biologics. Nat Rev Drug Discov. 2018 Nov 30. DOI:10.1038/nrd.2018.183.

Aprahamian M, Michel C, Humbert $\mathrm{W}$, et al. Transmucosal passage of polyalkylcyanoacrylate nanocapsules as a new drug carrier in the small intestine. Biol Cell. 1987;61(1-2):69-76.

Arbit E, Kidron M. Oral Insulin Delivery in a Physiologic Context: Review. J Diabetes Sci Technol. 2017;11(4):825-832. DOI:10.1177/1932296817691303.

Arias JL, Reddy LH, Othman M, et al. Squalene based nanocomposites: a new platform for the design of multifunctional pharmaceutical theragnostics. ACS Nano. 2011;5(2):1513-1521. DOI:10.1021/nn1034197.

Arias JL, Gallardo V, Gómez-Lopera SA, et al. Synthesis and characterization of poly(ethyl-2cyanoacrylate) nanoparticles with a magnetic core. J Control Release. 2001;77(3):309-321.

Åslund AKO, Sulheim E, Snipstad S, et al. Quantification and Qualitative Effects of Different PEGylations on Poly(butyl cyanoacrylate) Nanoparticles. Mol Pharm. 2017;14(8):2560-2569. DOI:10.1021/acs.molpharmaceut.6b01085.

Baldrick P. Pharmaceutical excipient development: the need for preclinical guidance. Regul Toxicol Pharmacol. 2000;32(2):210-218. DOI:10.1006/rtph.2000.1421.

Balland $\mathrm{O}$, Pinto-Alphandary $\mathrm{H}$, Viron $\mathrm{A}$, et al. Intracellular distribution of ampicillin in murine macrophages infected with Salmonella typhimurium and treated with $(3 \mathrm{H})$ ampicillin-loaded nanoparticles. J Antimicrob Chemother. 1996;37(1):105-115.

Balleño JA, Mendizábal-Ruiz AP, Saade H, et al. Ibuprofen Release from Poly(ethyl cyanoacrylate) Nanoparticles Prepared by Semicontinuous Heterophase Polymerization. Int J Polym Sci. 2018, Article ID 4527203. DOI:10.1155/2018/4527203

Bangham AD, Standish MM, Watkins JC. Diffusion of univalent ions across the lamellae of swollen phospholipids. J Mol Biol. 1965;13(1):238-252.

Banting FG, Best CH. The internal secretion of the pancreas. J Lab Clin Med. 1922;7:251-266.

Barraud L, Merle P, Soma E, et al. Doxorubicin-loaded nanoparticles shows increased cytotoxicity efficacy against hepatocellular carcinoma cells in vitro and in vivo. J Hepathol 2002;36:82. DOI:10.1016/S0168-8278(02)80281-1

Barraud L, Merle P, Soma E, et al. Increase of doxorubicine sensitivity by doxorubicin-loading into nanoparticles for hepatocellular carcinoma cells in vitro and in vivo. J Hepatol. 2005;42:736-743. DOI:10.1016/j.jhep.2004.12.035

Barrenholz Y. Doxil ${ }^{\circledR}$ - The First FDA-approved nano-drug: Lessons learned. J Control Rel. 2012;160:117134.

Batista P, Castro PM, Madureira AR, et al. Recent insights in the use of nanocarriers for the oral delivery of bioactive proteins and peptides. Peptides. 2018;101:112-123. DOI:10.1016/j.peptides.2018.01.002

Bawa KK, Oh JK. Stimulus-Responsive Degradable Polylactide-Based Block Copolymer Nanoassemblies for Controlled/Enhanced Drug Delivery. Mol Pharm. 2017;14(8):2460-2474. DOI:10.1021/acs.molpharmaceut.7b00284 
Bazile D, Prud'homme C, Bassoullet MT, et al. Stealth Me. PEG-PLA Nanoparticles Avoid Uptake by the Mononuclear Phagocytes System. J Pharm Sci. 1995;84:493-498.

Beloqui A, des Rieux A, Préat V. Mechanisms of transport of polymeric and lipidic nanoparticles across the intestinal barrier. Adv Drug Deliv Rev. 2016;106(Pt B):242-255. DOI:10.1016/j.addr.2016.04.014.

Bennis S, Chapey C, Couvreur P, et al. Enhanced cytotoxicity of doxorubicin encapsulated in polyisohexylcyanoacrylate nanospheres against multidrug-resistant tumour cells in culture. Eur J Cancer. 1994;30A(1):89-93.

Birrenbach G, Speiser PP. Polymerized micelles and their use as adjuvants in immunology. J Pharm Sci. 1976;65(12):1763-1766

Bertrand N, Leroux JC. The journey of a drug-carrier in the body: an anatomo-physiological perspective, J Control Release. 2012;161(2):152-163. doi: 10.1016/j.jconrel.2011.09.098.

Blanco E, Shen H, Ferrari M. Principles of nanoparticle design for overcoming biological barriers to drug delivery. Nat Biotechnol. 2015;33(9):941-951. DOI:10.1038/nbt.3330

Blume G, Cevc G. Liposomes for the sustained drug release in vivo. Biochim Biophys Acta. 1990;1029(1):91-97.

Bobo D, Robinson KJ, Islam J, et al. Nanoparticle-Based Medicines: A Review of FDA-Approved Materials and Clinical Trials to Date. Pharm Res. 2016;33(10):2373-2387. DOI:10.1007/s11095-0161958-5.

Bosch F, Rosich L. The contributions of Paul Ehrlich to pharmacology: A tribute on the occasion of the centenary of his Nobel Prize. Pharmacology. 2008;82:171-179. DOI:10.1159/000149583.

Brambilla D, Le Droumaguet B, Nicolas J, et al. Nanotechnologies for Alzheimer's disease: diagnosis, therapy, and safety issues. Nanomedicine. 2011;7(5):521-540. DOI:10.1016/j.nano.2011.03.008.

Brambilla D, Verpillot R, Le Droumaguet B, et al. PEGylated nanoparticles bind to and alter amyloidbeta peptide conformation: toward engineering of functional nanomedicines for Alzheimer's disease. ACS Nano. 2012;6(7):5897-5908. DOI:10.1021/nn300489k.

Brigger I, Morizet J, Aubert G, et al. Poly(ethylene glycol)-coated hexadecylcyanoacrylate nanospheres display a combined effect for brain tumor targeting. J Pharmacol Exp Ther. 2002;303(3):928-936.

Brigger I, Dubernet C, Couvreur P. Nanoparticles in cancer therapy and diagnosis. Adv Drug Deliv Rev. 2002;54(5):631-51.DOI:10.1016/S0169-409X(02)00044-3.

Brigger I, Morizet J, Laudani L, et al. Negative preclinical results with stealth nanospheresencapsulated Doxorubicin in an orthotopic murine brain tumor model, J Control Release. 2004;100(1):29-40.

Bui DT, Nicolas J, Maksimenko A, et al. Multifunctional squalene-based prodrug nanoparticles for targeted cancer therapy. Chem Commun (Camb). 2014;50(40):5336-5338. DOI:10.1039/c3cc47427e.

Bulbake U, Doppalapudi S, Kommineni N, et al. Liposomal Formulations in Clinical Use: An Updated Review. Pharmaceutics. 2017;9(2):E12. DOI: 10.3390/pharmaceutics9020012 
Cabeza L, Ortiz R, Arias JL, et al. Enhanced antitumor activity of doxorubicin in breast cancer through the use of poly(butylcyanoacrylate) nanoparticles. Int J Nanomedicine. 2015;10:1291-1306. DOI:10.2147/IJN.S74378.

Calvo P, Remuñán-López C, Vila-Rato JL, et al. Novel hydrophilic chitosan-polyethylene oxide nanoparticles as protein carriers. J Applied Polym Sci. 1997;63:125-132.

Calvo P, Gouritin B, Brigger I, et al. PEGylated polycyanoacrylate nanoparticles as vector for drug delivery in prion diseases. J Neurosci Methods. 2001a;111(2):151-155.

Calvo P, Gouritin B, Chacun H, et al. Long-circulating PEGylated polycyanoacrylate nanoparticles as new drug carrier for brain delivery. Pharm Res. 2001b;18(8):1157-1166.

Calvo P, Gouritin B, Villarroya H, et al. Quantification and localization of PEGylated polycyanoacrylate nanoparticles in brain and spinal cord during experimental allergic encephalomyelitis in the rat, Eur J Neurosci. 2002;15(8):1317-1326.

Cappel MJ, Kreuter J. Effect of nanoparticles on transdermal drug delivery. J Microencapsul. 1991;8(3):369-374.

Card JW, Magnuson BA. A review of the efficacy and safety of nanoparticle-based oral insulin delivery systems. Am J Physiol Gastrointest Liver Physiol. 2011;301(6):G956-967. DOI:10.1152/ajpgi.00107.2011.

Carradori D, Balducci C, Re F, et al. Antibody-functionalized polymer nanoparticle leading to memory recovery in Alzheimer's disease-like transgenic mouse model, Nanomedicine. 2018;14(2):609-618. doi: 10.1016/j.nano.2017.12.006.

Caster JM, Patel AN, Zhang T, et al. Investigational nanomedicines in 2016: a review of nanotherapeutics currently undergoing clinical trials. Wiley Interdiscip Rev Nanomed Nanobiotechnol. 2017;9(1):e1416. DOI:10.1002/wnan.1416.

Chan CKW, Zhang L, Cheng CK, et al. Recent Advances in Managing Atherosclerosis via Nanomedicine. Small. 2018;14(4): 1702793. DOI:10.1002/smll.201702793.

Charrueau C, Zandanel C. Associating Drugs with Polymer Nanoparticles: A Challenge. In Vauthier C, Ponchel G, editors. Polymer nanoparticles for nanomedicines. Cham (Switzerland): Springer2016. p. 381-437.

Chauvierre C, Labarre D, Couvreur P, Vauthier C. Novel polysaccharide-decorated poly(isobutyl cyanoacrylate) nanoparticles. Pharm Res. 2003;20(11):1786-1793.

Chavany C, Le Doua T, Couvreur P, et al. Polyalkylcyanoacrylate nanoparticles as polymeric carriers for antisense oligonucleotides. Pharm Res. 1992;9(4):441-449.

Chiannilkulchai N, Driouich Z, Benoit JP, et al. Doxorubicin-loaded nanoparticles: increased efficiency in murine hepatic metastases. Sel Cancer Ther. 1989;5(1):1-11.

Chiannilkulchai N, Ammoury N, Caillou B, et al. Hepatic tissue distribution of doxorubicin-loaded nanoparticles after i.v. administration in reticulosarcoma M 5076 metastasis-bearing mice. Cancer Chemother Pharmacol. 1990;26(2):122-6.

Choi YK, Bae YH, Kim SW. Block copolymer nanoparticles of ethylene oxide and isobutyl cyanoacrylate, Macromolecules. 1995;28:8419-8421. Doi: 10.1021/ma00128a062. 
Christopher AF, Kaur RP, Kaur G, et al. MicroRNA therapeutics: Discovering novel targets and developing specific therapy. Perspect Clin Res. 2016;7(2):68-74. DOI:10.4103/2229-3485.179431.

Chung SW, Hil-lal TA, Byun Y. Strategies for non-invasive delivery of biologics. J Drug Target. 2012;20(6):481-501. DOI:10.3109/1061186X.2012.693499.

Cicha I, Chauvierre C, Texier I, et al. From design to the clinic: practical guidelines for translating cardiovascular nanomedicine. Cardiovasc Res. 2018;114(13):1714-1727. DOI:10.1093/cvr/cvy219.

Clogston JD, Patri AK. Importance of physicochemical characterization prior to immunological studies. In: Dobrovolskaia MA, McNeil SE, editors. Handbook of Immunological Properties of Engineered Nanomaterials. Singapore (Singapore): World Scientific Publishing Ltd.; 2013. p. 25-52.

Colin de Verdière A, Dubernet $C$, Nemati F, et al. Uptake of doxorubicin from loaded nanoparticles in multidrug-resistant leukemic murine cells, Cancer Chemother Pharmacol. 1994;33(6):504-508.

Colin de Verdière A, Dubernet C, et al. Reversion of multidrug resistance with polyalkylcyanoacrylate nanoparticles : towards a mechanism of action. Br J Cancer. 1997;76:198-205.Coty JB, Eleamen Oliveira E, Vauthier C. Tuning complement activation and pathway through controlled molecular architecture of dextran chains in nanoparticle corona, Int J Pharm. 2017;532(2):769-778. doi: 10.1016/j.ijpharm.2017.04.048

Coty JB, Varenne F, Benmalek A, et al. Characterization of nanomedicines' surface coverage using molecular probes and capillary electrophoresis, Eur J Pharm Biopharm. 2018;130:48-58. doi: 10.1016/j.ejpb.2018.06.014

Coty JB, Noiray M, Vauthier C. Assessment of Complement Activation by Nanoparticles: Development of a SPR Based Method and Comparison with Current High Throughput Methods, Pharm Res. 2018;35(7):129. doi: 10.1007/s11095-018-2406-5.

Couplan RE. Electron microscopic observations on the structure of the rat adrenal medulla. I The ultrastructure and organization of chromaffin cells in the normal adrenal medulla. J Anat. 1965;99:231-254.

Couvreur P, Tulkens $\mathrm{P}$, Roland $\mathrm{M}$, et al. Nanocapsules: a new type of lysosomotropic carrier. FEBS Lett. 1977;84(2):323-326.

Couvreur P, Kante B, Roland M, et al. Polycyanoacrylate nanocapsules as potential lysosomotropic carriers: preparation, morphological and sorptive properties. J Pharm Pharmacol. 1979a;31(5):331332.

Couvreur P., Kante B, Roland M, et al. Adsorption of antineoplastic drugs to polyalkylcyanoacrylate nanoparticles and their release in calf serum. J Pharm Sci 1979b;68:1521-1624.

Couvreur P, Roland M, Speiser P. Brevet Belge d'Invention Nº 869.107 (1979c)

Couvreur P, Roland M, Speiser P. Demande de Brevet Européen Nº 79870017.5 (1979d)

Couvreur $\mathrm{P}$, Kante $\mathrm{B}$, Lenaerts $\mathrm{V}$, et al. Tissue distribution of antitumor drugs associated with polyalkylcyanoacrylate nanoparticles. J. Pharm. Sci. 69, 199-202 (1980a)

Couvreur P, Kante B, Roland M. Les vecteurs lysosomotropes. J. Pharm. Belg. 35, 51-60 (1980b)

Couvreur P, Roland M, Speiser P. Demande de Brevet Français Nº 8108172 (1981) 
Couvreur P, Roland M, Speiser P. United State Patent $N^{\circ} 4328332$ (1982a)

Couvreur P, Kante B, Grislain L, et al. Toxicity of polyalkylcyanoacrylate nanoparticles II: Doxorubicinloaded nanoparticles. J Pharm Sci. 1982b;71(7):790-792.

Couvreur P. Design of biodegradable polyalkylcyanoacrylate nanoparticles as a drug carrier. In: Davis. SS, Illum L, McVie JG, Tomlinson E, editors. Microspheres and Drug Therapy. Amsterdam (The Netherland): Elsevier Science Ltd.; 1984. p. 103-115.

Couvreur P. Polyalkylcyanoacrylates as colloidal drug carriers. Crit Rev Therap Drug carrier system. 1988;5:1-20.

Couvreur P, Roblot-Treupel L, Poupon MF, et al. Nanoparticles as microcarriers for anticancer drugs. Adv Drug Deliv Rev. 1990;5:200-230.

Couvreur P, Vauthier C. Polyalkylcyanoacrylate nanoparticles as drug carriers : present state and perspectives. J Control Rel. $1991 ; 17: 187-198$.

Couvreur P, Puisieux F. Nano- and microparticles for the delivery of polypeptides and proteins. Adv Drug Deliv Rev. 1993;10:141-162.

Couvreur P, Vauthier C. Nanotechnology: Intelligent design to treat complex diseases. Pharm Res. 2006;23:1417-1450

Couvreur P, Stella B, Reddy LH, et al. Squalenoyl nanomedicines as potential therapeutics. Nano Lett. 2006;6(11):2544-2548.

Couvreur P. " Squalenoylation": a new approach to the design of anticancer and antiviral nanomedicines. Bull Acad Natl Med. 2009;193(3):663-673; discussion 673-4.

Couvreur P. Nanoparticles in drug delivery : past, present and future. Adv Drug Deliv Rev. 2013;65:2123.

Cucchetti A, Piscaglia F, Pinna AD, et al. Efficacy and Safety of Systemic Therapies for Advanced Hepatocellular Carcinoma: A Network Meta-Analysis of Phase III Trials. Liver Cancer 2017;6:337348. DOI: $10.1159 / 000481314$

Cuvier C, Roblot-Treupel L, Millot JM, et al. Doxorubicin-loaded nanospheres bypass tumor cell multidrug resistance. Biochem Pharmacol. 1992;44(3):509-517.

Czuba E, Diop M, Mura C, et al. Oral insulin delivery, the challenge to increase insulin bioavailability: Influence of surface charge in nanoparticle system. Int J Pharm. 2018;542:47-55. DOI: 10.1016/j.ijpharm.2018.02.045.

Dai Q, Wilhelm S, Ding D, et al. Quantifying the Ligand-Coated Nanoparticle Delivery to Cancer Cells in Solid Tumors, ACS Nano. 2018;12(8):8423-8435. doi: 10.1021/acsnano.8b03900.

Damgé $C$, Michel C, Aprahamian $M$, et al. New approach for oral administration of insulin with polyalkylcyanoacrylate nanocapsules as drug carrier. Diabetes. 1988;37(2):246-251, 1988.

Damgé C, Vonderscher J, Marbach P, et al. Poly(alkyl cyanoacrylate) nanocapsules as a delivery system in the rat for octreotide, a long-acting somatostatin analogue. J Pharm Pharmacol. 1997;49(10):949954. 
Damgé C, Aprahamian M, Humbert W, et al. Ileal uptake of polyalkylcyanoacrylate nanocapsules in the rat. Pharm Pharmacol. 2000;52:1049-1056.

Damgé $\mathrm{C}$,Maincent $\mathrm{P}$, Ubrich $\mathrm{N}$. Oral delivery of insulin associated to polymeric nanoparticles in diabetic rats. J Control Release. 2007;117:163-170.

Danhier F, Ansorena E, Silva JM, et al. PLGA-based nanoparticles: An overview of biomedical applications. J Control Release. 2012;161:506-522. DOI:10.1016/j.jconrel.2012.01.043

Daoud-Mahammed S, Grossiord JL, Bergua T, et al. Self-assembling cyclodextrin based hydrogels for the sustained delivery of hydrophobic drugs. J Biomed Mater Res A. 2008;86(3):736-48.

Daoud-Mahammed S, Ringard-Lefebvre C, Razzouq N, et al. Spontaneous association of hydrophobized dextran and poly-beta-cyclodextrin into nanoassemblies. Formation and interaction with a hydrophobic drug. J Colloid Interface Sci. 2007;307(1):83-93.

Daoud-Mahammed S, Couvreur P, Bouchemal K, et al. Cyclodextrin and polysaccharide-based nanogels: entrapment of two hydrophobic molecules, benzophenone and tamoxifen. Biomacromolecules. 2009;10 (3):547-554.

Da Silva CG, Peters GJ, Ossendorp F, et al. The potential of multi-compound nanoparticles to bypass drug resistance in cancer. Cancer Chemother Pharmacol. 2017;80(5):881-894. DOI: 10.1007/s00280-017-3427-1.

De Duve C., Exploring Cells with a Centrifuge. Nobel Prize Lecture, 12 December 1974. Available from: https://www.nobelprize.org/prizes/medicine/1974/duve/lecture/ (accessed 12 December 2018.

de Duve C, de Barsy T, Poole B, et al. Commentary. Lysosomotropic agents. Biochem Pharmacol. 1974;23(18):2495-2531.

Delplace V, Couvreur P., Nicolas J. Recent trends in the design of anticancer polymer prodrug nanocarriers. Polymer Chem. 2014;5:1529-1544.

De Martimprey H, Vauthier C, Malvy C, et al. Polymer nanocarriers for the delivery of small fragments of nucleic acids: oligonucleotides and siRNA. Eur J Pharm Biopharm. 2009;71 (3):490-504.

Desai N. Challenges in development of nanoparticle-based therapeutics. AAPS J. 2012;14(2):282-295. DOI:10.1208/s12248-012-9339-4.

Desai JR, Ochoa S, Prins PA, et al. Systemic therapy for advanced hepatocellular carcinoma: an update. J Gastrointest Oncol. 2017; 8(2): 243-255. DOI:10.21037/jgo.2017.02.01.

Desgouilles S, Vauthier C, Bazile D, et al. The Design of Nanoparticles Obtained by Solvent Evaporation: A Comprehensive Study. Langmuir. 2003;19: 9504-9510.

Desmaële D, Gref R, Couvreur P. Squalenoylation: a generic platform for nanoparticular drug delivery. J Control Release. 2012;161(2):609-618. DOI: 10.1016/j.jconrel.2011.07.038.

des Rieux A, Fievez V, Garinot M, et al. Nanoparticles as potential oral delivery systems of proteins and vaccines: a mechanistic approach. J Control Release. 2006;116(1):1-27.

Diaz-Salmeron R, Ponchel G, Gallard JF, et al. Hierarchical supramolecular platelets from hydrophobically-modified polysaccharides and $\alpha$-cyclodextrin: Effect of hydrophobization and $\alpha$ cyclodextrin concentration on platelet formation. Int J Pharm. 2018;548(1):227-236. DOI:10.1016/j.ijpharm.2018.06.061. 
Dobrovolskaia MA, Shurin M, Shvedova AA. Current understanding of interactions between nanoparticles and the immune system. Toxicol Appl Pharmacol. 2016;299:78-89. DOI:10.1016/j.taap.2015.12.022.

Dormont F, Varna M, Couvreur P. Nanoplumbers : biomaterials to fight cardiovascular diseases. Materials Today. 2018;21:22-143. DOI:10.1016/j.mattod.2017.07.008

Douglas SJ, Davis SS, Illum L. Biodistribution of poly(butyl-2-cyanoacrylate) nanoparticles in rabbits. Int. J. Pharm. 1986;34:145-152.

Douglas SJ, Davis SS, Illum L. Nanoparticles in drug delivery. Crit Rev Ther Drug Carrier Syst. 1987;3(3):233-261.

Duncan R, Gaspar R. Nanomedicine(s) under the microscope. Mol. Pharmaceutics. 2011;8:2101-2141. DOI:10.1021/mp200394t

Duncan R, Richardson SC. Endocytosis and intracellular trafficking as gateways for nanomedicine delivery: opportunities and challenges, Mol Pharm. 2012;9(9):2380-402. doi: 10.1021/mp300293n

Duncan R. Nanomedicine(s) and their regulation: an overview. In B. Fadeel, editor. Handbook of safety assessment: from toxicological testing to personalize medicine. Singapore (Singapore): Pan Stanford Publishing; 2015. p. 1-30.

Duro-Castano A, Nebot VJ, Niño-Pariente A, et al. Capturing "Extraordinary" Soft-Assembled ChargeLike Polypeptides as a Strategy for Nanocarrier Design. Adv Mater. 2017;29(39): 1702888. DOI:10.1002/adma.201702888.

Dusinska M, Boland S, Saunders M, et al. Towards an alternative testing strategy for nanomaterials used in nanomedicine: lessons from NanoTEST. Nanotoxicology. 2015;9 (Suppl 1):118-132. DOI:10.3109/17435390.2014.991431.

El-Samaligy MS, Rohdewald P, Mahmoud HA. Polyalkyl cyanoacrylate nanocapsules. J Pharm Pharmacol. 1986;38(3):216-218.

El-Sawy HS, Al-Abd AM, Ahmed TA, et al. Stimuli-Responsive Nano-Architecture Drug-Delivery Systems to Solid Tumor Micromilieu: Past, Present, and Future Perspectives. ACS Nano. 2018;12(11):1063610664. DOI:10.1021/acsnano.8b06104.

Ehrlich P., Partial Cell Function. Nobel lecture. 11 December 1908. Available from https://www.nobelprize.org/prizes/medicine/1908/ehrlich/lecture/ (accessed 12 December 2018)

EU/3/04/229 EUDRACT 2006-004088-77: Clinical trial on Doxorubicin-Transdrug ${ }^{\circledR}$. https://www.clinicaltrialsregister.eu/ctr-search/trial/2006-004088-77/DE (accessed 23/11/2019)

Fattal E, Youssef M, Couvreur P, et al. Treatment of experimental salmonellosis in mice with ampicillinbound nanoparticles. Antimicrob Agents Chemother. 1989;33(9):1540-1543.

Fattal E, Vauthier C, Aynie I, et al. Biodegradable polyalkylcyanoacrylate nanoparticles for the delivery of oligonucleotides. J Control Release. 1998;53 (1-3):137-143.

Fattal E, Couvreur P, Dubernet C. Smart delivery of antisense oligonucleotides by anionic $\mathrm{pH}$-sensitive liposomes. Adv Drug Deliv Rev. 2004;56:931-946. 
Fattal E, Barratt G. Nanotechnologies and controlled release systems for the delivery of antisense oligonucleotides and small interfering RNA. $\mathrm{Br} J$ Pharmacol. 2009;157(2):179-194. DOI:10.1111/j.1476-5381.2009.00148.x.

Fattal E, Couvreur P. Polymeric nanoparticles and microparticles as carriers for antisense oligonucleotides. In Couvreur P, Malvy C, editors. Pharmaceutical aspects of oligonucleotides. Philaderphia (PA): Taylor \& Francis Group; 2000, p. 129-147.

Feng J, Lepetre-Mouelhi S, Couvreur P. Design, Preparation and Characterization of Modular Squalenebased Nanosystems for Controlled Drug Release. Curr Top Med Chem. 2017;17:2849-2865. DOI:10.2174/1568026617666170719171728

Ferreira MP, Balasubramanian V, Hirvonen J, et al. Advanced Nanomedicines for the Treatment and Diagnosis of Myocardial Infarction and Heart Failure. Curr Drug Targets. 2015;16(14):1682-1697.

Fire A, Xu S, Montgomery MK, et al. Potent and specific genetic interference by double-stranded RNA in Caenorhabditis elegans. Nature. 1998;391(6669):806-811.

Fisher NF. The absorption of insulin from the intestine, vaginal and scrotal sac. Amer J Physiol. 1923;67:65-71. DOI:10.1152/ajplegacy.1923.67.1.65

Fonte $\mathrm{P}$, Araújo F, Silva $\mathrm{C}$, et al. Polymer-based nanoparticles for oral insulin delivery: Revisited approaches. Biotechnol Adv. 2015;33(6 Pt 3):1342-1354. DOI:10.1016/j.biotechadv.2015.02.010.

Fornaguera C, García-Celma MJ. Personalized Nanomedicine: A Revolution at the Nanoscale. J Pers Med. 2017;7(4): E12. doi: 10.3390/jpm7040012.

Fosgerau K, Hoffmann T. Peptide therapeutics: current status and future directions. Drug Discov Today. 2015;20:122-128. DOI: 10.1016/j.drudis.2014.10.003.

Friberg S, Nyström AM. NANOMEDICINE: will it offer possibilities to overcome multiple drug resistance in cancer? J Nanobiotechnol. 2016;14:17. DOI:10.1186/s12951-016-0172-2.

Fusser M, Øverbye A, Pandya AD, et al. Cabazitaxel-loaded Poly(2-ethylbutyl cyanoacrylate) nanoparticles improve treatment efficacy in a patient derived breast cancer xenograft, J Control Release. 2019;293:183-192. doi: 10.1016/j.jconrel.2018.11.029.

Gao X, Lowry GV. Progress towards standardized and validated characterizations for measuring physicochemical properties of manufactured nanomaterials relevant to nano health and safety risks. Nanolmpact. 2018; 9:14-30. DOI:10.1016/j.impact.2017.09.002.

Gao S, Xu Y, Asghar S, et al. Polybutylcyanoacrylate nanocarriers as promising targeted drug delivery systems. J Drug Target. 2015;23(6):481-496. DOI:10.3109/1061186X.2015.1020426.

Garcia-Garcia E, Andrieux K, Gil S, et al. Colloidal carriers and blood-brain barrier (BBB) translocation: a way to deliver drugs to the brain? Int J Pharm. 2005a;298(2):274-292.

Garcia-Garcia E, Gil S, Andrieux K, et al. A relevant in vitro rat model for the evaluation of blood-brain barrier translocation of nanoparticles. Cell Mol Life Sci. 2005b;62(12):1400-1408.

Garcia-Fuentes M, Alonso MJ. Chitosan-based drug nanocarriers: where do we stand? J Control Release. 2012;161(2):496-504. DOI:10.1016/j.jconrel.2012.03.017.

Gasco MR, Trotta M. Nanoparticles from microemulsions. Int J Pharm. 1986;29:267-268. 
Gaudin A, Andrieux K, Couvreur P. Nanomedicines and stroke: Toward translational research. J Drug Deliv Sci Technol. 201530,278-299. DOI: 10.1016/j.jddst.2015.07.018.

Gedawy A, Martinez J, Al-Salami H, et al. Oral insulin delivery: existing barriers and current counterstrategies. J Pharm Pharmacol. 2018;70(2):197-213. DOI:10.1111/jphp.12852.

Germann UA, Pastan I, Gottesman MM. P-glycoproteins: mediators of multidrug resistance. Semin Cell Biol. 1993;4(1):63-76

Giglia JL, Antonia SJ, Berk LB, et al. Systemic therapy for advanced hepatocellular carcinoma: past, present, and future. Cancer Control. 2010;17(2):120-129.

Gottesman MM, Pastan I. Biochemistry of multidrug resistance mediated by the multidrug transporter. Annu Rev Biochem. 1993;62:385-427.

Gottesman, M.M.; Fojo, T.; Bates, S.E. Multidrug resistance in cancer: Role of ATP-dependent transporters. Nat Rev Cancer 2002;2:48-58.

Gottesman MM, Pastan IH. The Role of Multidrug Resistance Efflux Pumps in Cancer: Revisiting a JNCI Publication Exploring Expression of the MDR1 (P-glycoprotein) Gene. J Natl Cancer Inst. 2015;107(9):djv222. DOI:10.1093/jnci/djv222.

Graf A, McDowell A, Rades T. Poly(alkylcyanoacrylate) nanoparticles for enhanced delivery of therapeutics - is there real potential? Expert Opin Drug Deliv. 2009;6(4):371-87. DOI:10.1517/17425240902870413.

Gref R, Minamitake Y, Peracchia MT, et al. Biodegradable long-circulating polymeric nanospheres. Science. 1994;263(5153):1600-1603.

Gref R, Amiel C, Molinard K, et al. New self-assembled nanogels based on host-guest interactions: characterization and drug loading. J Control Release. 2006;111(3):316-324.

Gregoriadis G. Drug entrapment in liposomes. Febs Letter. 1973;36:292-296.

Gregoriadis G, Neerunjun DE, Hunt R. Fate of a liposome-associated agent injected into normal and tumour-bearing rodents. Attempts to improve localization in tumour tissues. Life Sci. 1977;21(3):357-369.

Gregoriadis G. Liposomology: Delivering the message. J Liposome Res. 2018; 28:1-4.

Griffin BT, Guo J, Presas E, et al. Pharmacokinetic, pharmacodynamic and biodistribution following oral administration of nanocarriers containing peptide and protein drugs. Adv Drug Deliv Rev. 2016;106(Pt B):367-380. DOI:10.1016/j.addr.2016.06.006.

Gulyaev AE, Gelperina SE, Skidan IN, et al. Significant transport of doxorubicin into the brain with polysorbate 80-coated nanoparticles. Pharm Res. 1999;16(10):1564-1569.

Gurny R., Peppas NA, Harrington DD, et al. Development of biodegradable and injectable lattices for controlled release of potent drugs. Drug Dev Ind Pharm. 1981;7:1-25.

Hainfeld JF, Lin L, Slatkin DN, et al. Gold nanoparticle hyperthermia reduces radiotherapy dose, Nanomedicine. 2014;10(8):1609-1617. doi: 10.1016/j.nano.2014.05.006.

Hamidi M, Azadi A, Rafiei P. Hydrogel nanoparticles in drug delivery. Adv Drug Deliv Rev. 2008;60:16381649. DOI: 10.1016/j.addr.2008.08.002. 
Hare $\mathrm{Jl}$, Lammers $\mathrm{T}$, Ashford $\mathrm{MB}$, et al. Challenges and strategies in anti-cancer nanomedicine development: An industry perspective. Adv Drug Deliv Rev. 2017;108:25-38. DOI:10.1016/j.addr.2016.04.025.

Hassanzadeh P, Atyabi F, Dinarvand R. Linkers: The key elements for the creation of efficient nanotherapeutics. J Control Release. 2018;270:260-267. DOI:10.1016/j.jconrel.2017.12.007.

He J, Li R, Sun X, et al. Effects of Calcium Alginate Submicroparticles on Seed Germination and Seedling Growth of Wheat (Triticum aestivum L.). Polymers 2018;10:1154. DOI:10.3390/polym10101154.

Hillaireau H, Couvreur P. Nanocarriers' entry into the cell: relevance to drug delivery. Cellular and molecular life sciences 2009;66 (17):2873-2896.

Hillaireau H, Le Doan T, Appel M, et al. Hybrid polymer nanocapsules enhance in vitro delivery of azidothymidine-triphosphate to macrophages. J Control Release. 2006;116(3):346-352.

Hillaireau H, Le Doan T, Chacun H, et al. Encapsulation of mono- and oligo-nucleotides into aqueouscore nanocapsules in presence of various water-soluble polymers. Int J Pharm. 2007;331(2):148152. Epub 2006 Oct 27

Ho YT, Adriani G, Beyer S, et al. A Facile Method to Probe the Vascular Permeability of Nanoparticles in Nanomedicine Applications. Sci Rep. 2017;7(1):707. DOI:10.1038/s41598-017-00750-3.

Hoffman AS. The origins and evolution of "controlled" drug delivery systems. J Control Release. 2008;132(3):153-163. DOI:10.1016/j.jconrel.2008.08.012.

Horcajada P, Chalati T, Serre C, et al. "Porous metal-organic-framework nanoscale carriers as a potential platform for drug delivery and imaging". Nature Material. 2010;9:172-178.

Horcajada P, Gref R, Baati T, et al. Metal-organic frameworks in biomedicine. Chem Rev. 2012;112(2):1232-1268. DOI: 10.1021/cr200256v.

Housman G, Byler S, Heerboth S, et al. Drug resistance in cancer: an overview. Cancers (Basel). 2014;6(3):1769-1792. DOI:10.3390/cancers6031769

Hu Q, Chen Q, Gu Z. Advances in transformable drug delivery systems. Biomaterials. 2018;178:546558. DOI:10.1016/j.biomaterials.2018.03.056.

Hu X, Yang F, Liao Y, et al. Cholesterol-PEG co-modified poly (N-butyl) cyanoacrylate nanoparticles for brain delivery: in vitro and in vivo evaluations. Drug Deliv. 2017;24(1):121-132. DOI:10.1080/10717544.2016.1233590.

Ibegbu DM, Boussahel A, Cragg SM, et al. Nanoparticles of alkylglyceryl dextran and poly(ethyl cyanoacrylate) for applications in drug delivery: Preparation and characterization. Int J Polym Mater Polym Biomater. 2017;66:265-279, 2017. DOI: 10.1080/00914037.2016.1201827.

Ilinskaya AN, Dobrovolskaia MA. Understanding the immunogenicity and antigenicity of nanomaterials: Past, present and future. Toxicol Appl Pharmacol. 2016;299:70-77. DOI:10.1016/j.taap.2016.01.005.

Illum L, Jones PDE, Kreuter J, et al. Adsorption of monoclonal antibodies to polyhexylcyanoacrylate nanoparticles and subsequent immunospecific binding to tumour cells in vitro. Int J Pharm. 1983;17:65-76. 
Illum L, Jones PDE, Baldwin RW, et al. Tissue distribution of Poly(hexyl 2-cyanoacrylate) nanoparticles coated with monoclonal antibodies in mice bearing human tumor xenografts. J Pharmacol Exp Ther. 1984;230:733-220.

Islam N, Ferro V. Recent advances in chitosan-based nanoparticulate pulmonary drug delivery. Nanoscale. 2016;8(30):14341-14358. DOI: 10.1039/c6nr03256g.

James R, Manoukian OS, Kumbar SG. Poly(lactic acid) for delivery of bioactive macromolecules. Adv Drug Deliv Rev. 2016;107:277-288. DOI:10.1016/j.addr.2016.06.009.

Janagam DR, Wu L, Lowe TL. Nanoparticles for drug delivery to the anterior segment of the eye. Adv Drug Deliv Rev. 2017;122:31-64. DOI:10.1016/j.addr.2017.04.001.

Jeon SI, Lee JH, Andrade JD, De Gennes PG. Protein-surface interactions in the presence of polyethylene oxide I. Simplified theory. J Coll Interf Sci. 1991;142:149-158 DOI:10.1016/00219797(91)90043-8

Jiang L, Lin J, Taggart C, et al. Nanodelivery strategies for the treatment of multidrug-resistant bacterial infections. J Interdiscip Nanomed 2018;3:111-121. DOI: 10.1002/jin2.48.

Jin $\mathrm{XF}, \mathrm{Xu} \mathrm{Y}$, Shen J, et al. Chitosan-glutathione conjugate-coated poly(butyl cyanoacrylate) nanoparticles: Promising carriers for oral thymopentin delivery. Carbohydr Polym. 2011;86:51-57

Juenet $M$, Aid-Launais $R$, Li B, et al. Thrombolytic therapy based on fucoidan-functionalized polymer nanoparticles targeting P-selectin. Biomaterials. 2018;156:204-216. DOI:10.1016/j.biomaterials.2017.11.047.

Juliano R. The delivery of therapeutic oligonucleotides. Nucleic Acids Res. 2016;44(14):6518-6548. DOI:10.1093/nar/gkw236.

Kafka AP, McLeod BJ, Radesa T, et al. Release and bioactivity of PACA nanoparticles containing D-Lys6GnRH for brushtail possum fertility control. J Contr Rel. 2011;149:307-313.

Kalepu S, Nekkanti V. Insoluble drug delivery strategies: review of recent advances and business prospects. Acta Pharm Sin B. 2015;5:442-453.

Kamaly N, Xiao Z, Valencia PM, et al. Targeted polymeric therapeutic nanoparticles: design, development and clinical translation. Chem Soc Rev. 2012;41(7):2971-3010. DOI:10.1039/c2cs15344k.

Kante B, Couvreur P, Dubois-Krack G, et al. Toxicity of polyalkylcyanoacrylate nanoaprticles I: free nanoparticles. J Pharm Sci. 1982:71:786-790.

Kante $B$, Couvreur $P$, Lenaerts $V$, et al. Tissue distribution of $\left[{ }^{3} \mathrm{H}\right]$ actinomycine $D$ adsorbed on polybutylcyanoacrylate nanoparticles. Int J Pharm. 1980;7:45-53.

Karatas H, Aktas Y, Gursoy-Ozdemir Y, et al. A nanomedicine transports a peptide caspase-3 inhibitor across the blood-brain barrier and provides neuroprotection. J Neurosci. 2009;29(44):13761-13769. DOI:10.1523/JNEUROSCI.4246-09.2009.

Karra N, Benita S. The ligand nanoparticle conjugation approach for targeted cancer therapy. Curr Drug Metab. 2012;13(1):22-41

Kattan J, Droz JP, Couvreur P, et al. Phase I clinical trial and pharmacokinetic evaluation of doxorubicin carried by polyisohexylcyanoacrylate nanoparticles. Invest New Drugs. 1992;10:191-192. 
Keating GM, Santoro A. Sorafenib: a review of its use in advanced hepatocellular carcinoma. Drugs. 2009;69(2):223-240. DOI: 10.2165/00003495-200969020-00006

Key J, Park K. Multicomponent, Tumor-Homing Chitosan Nanoparticles for Cancer Imaging and Therapy. Int J Mol Sci. 2017;18(3): E594. DOI:10.3390/ijms18030594

Kim HR, Andrieux K, Delomenie $\mathrm{C}$, et al. Analysis of plasma protein adsorption onto PEGylated nanoparticles by complementary methods: 2-DE, CE and Protein Lab-on-chip system. Electrophoresis. 2007a;28(13):2252-2261

Kim HR, Andrieux K, Gil S, et al. Translocation of poly(ethylene glycol-co-hexadecyl)cyanoacrylate nanoparticles into rat brain endothelial cells: role of apolipoproteins in receptor-mediated endocytosis. Biomacromolecules. 2007b;8(3):793-799

Kopecek J, Kopecková P. HPMA copolymers: origins, early developments, present, and future. Adv Drug Deliv Rev. 2010;62(2):122-149. DOI:10.1016/j.addr.2009.10.004.

Kramer PA. Albumin microspheres as vehicles for achieving specificity in drug delivery. J Pharm Sci. 1974;63:1646-1647.

Kreuter J. Neue Adjuvantien auf polymethylmethacrylatbasis. Dissertation ETH Zurich Nr.5417, 1974.

Kreuter J. Evaluation of nanoparticles as drug delivery systems I: Preparation methods. Pharm Acta Helv. 1983;58:196-209.

Kreuter J. Physicochemical characterization of polyacrylic nanoparticles. Int J Pharm. 1983a;14:43-58.

Kreuter J. Poly(alkyl acrylate) nanoparticles. Methods in enzymology 1985;112:129-138.

Kreuter J. Possibilities of using nanoparticles as carriers for drugs and vaccines. J Microencapsulation. 1988;5:115-127.

Kreuter J. Nanoparticles. In: Kreuter J, editor Ed. Colloidal drug delivery systems. New York (NY): Marcel Dekker Inc.; 1994. P. 219-242.

Kreuter J, Alyautdin RN, Kharkevich DA, et al. Passage of peptides through the blood-brain barrier with colloidal polymer particles (nanoparticles). Brain Res. 1995;674(1):171-174.

Kreuter J. Nanoparticulate systems for brain delivery of drugs. Adv Drug Deliv Rev. 2001;47(1):65-81.

Kreuter J, Shamenkov D, Petrov V, et al. Apolipoprotein-mediated transport of nanoparticle-bound drugs across the blood-brain barrier, J Drug Target. 2002;10:317-325.

Kreuter J., Nanoparticles - a historical perspective. Int J Pharm. 2007; 331:1-10.

Kreuter J. Drug delivery to the central nervous system by polymeric nanoparticles: what do we know? Adv Drug Deliv Rev. 2014;71:2-14. doi: 10.1016/j.addr.2013.08.008.

Krukemeyer MG, Krenn V, Huebner F, et al. History and possible uses of nanomedicine based on nanoparticles and nanotechnological progress. J Nanomed Nanotechnol. 2015;6:1000336. DOI:10.4172/2157-7439.1000336.

Kunjachan S, Ehling J, Storm G, et al. Noninvasive Imaging of Nanomedicines and Nanotheranostics: Principles, Progress, and Prospects, Chem Rev. 2015;115(19):10907-10937. doi:

10.1021/cr500314d. 
Lacombe S, Porcel E, Scifoni E. Particle therapy and nanomedicine: state of art and research perspectives. Cancer Nanotechnol. 2017;8:9. DOI: 10.1186/s12645-017-0029-x.

Laham A, Claperon N, Durussel JJ, et al. Intracarotidal administration of liposomally-entrapped ATP: improved efficiency against experimental brain ischemia. Pharmacol Res Commun. 1988;20(8):699705.

Lai P, Daear W, Löbenberg R, Prenner EJ. Overview of the preparation of organic polymeric nanoparticles for drug delivery based on gelatine, chitosan, poly(d,I-lactide-co-glycolic acid) and polyalkylcyanoacrylate. Colloids Surf B Biointerfaces. 2014;118:154-163. DOI:10.1016/j.colsurfb.2014.03.017

Lakkireddy HR, Urmann M, Besenius M, et al. Oral delivery of diabetes peptides - Comparing standard formulations incorporating functional excipients and nanotechnologies in the translational context. Adv Drug Deliv Rev. 2016;106(Pt B):196-222. DOI:10.1016/j.addr.2016.02.011

Lakkireddy HR, Bazile D. Building the design, translation and development principles of polymeric nanomedicines using the case of clinically advanced poly(lactide(glycolide))-poly(ethylene glycol) nanotechnology as a model: An industrial viewpoint. Adv Drug Deliv Rev. 2016;107:289-332. DOI:10.1016/j.addr.2016.08.012.

Lakkireddy HR, Bazile DV, Nanocarriers for drug routing - towards a new era. J Drug Target. this volume

Lambert G, Fattal E, Pinto-Alphandary H, et al. Polyisobutylcyanoacrylate nanocapsules containing an aqueous core as a novel colloidal carrier for the delivery of oligonucleotides, Pharm Res. 2000;17(6):707-714.

Lambert G, Bertrand JR, Fattal E, et al. EWS fli-1 antisense nanocapsules inhibits ewing sarcomarelated tumor in mice, Biochem Biophys Res Commun. 2000;279(2):401-406.

Lamch L, Pucek A, Kulbacka J, et al. Recent progress in the engineering of multifunctional colloidal nanoparticles for enhanced photodynamic therapy and bioimaging. Adv Colloid Interface Sci. 2018;261:62-81. DOI:10.1016/j.cis.2018.09.002.

Lammers T, Kiessling F, Hennink WE, et al. Nanotheranostics and image-guided drug delivery: current concepts and future directions, Mol Pharm. 2010;7(6):1899-1912. doi: 10.1021/mp100228v.

Lammers T, Kiessling F, Hennink WE, et al. Drug targeting to tumors: principles, pitfalls and (pre-) clinical progress. J Control Release. 2012;161(2):175-187. DOI:10.1016/j.jconrel.2011.09.063.

Lau JL, Dunn MK. Therapeutic peptides: Historical perspectives, current development trends, and future directions. Bioorg Med Chem. 2018;26:2700-2707. DOI:10.1016/j.bmc.2017.06.052

Layre A, Couvreur P, Chacun H, et al. Novel composite core-shell nanoparticles as busulfan carriers. J Control Release. 2006;111(3):271-280.

Le Droumaguet B, Nicolas J, Brambilla D, et al. Versatile and efficient targeting using a single nanoparticulate platform: application to cancer and Alzheimer's disease. ACS Nano. 2012;6(7):5866-5879. DOI:10.1021/nn3004372

Lee MS, Dees EC, Wang AZ. Nanoparticle-Delivered Chemotherapy: Old Drugs in New Packages. Oncology (Williston Park). 2017;31(3):198-208. 
Lee RC, Feinbaum RL, Ambros V. The C. elegans heterochronic gene lin-4 encodes small RNAs with antisense complementarity to lin-14. Cell. 1993;75(5):843-854.

Lee Ventola C. Progress in nanomedicines; Approved and investigational nanodrugs. P T. 2017;42:742755.

Lee BK, Yun Y, Park K. PLA micro- and nano-particles. Adv Drug Deliv Rev. 2016 5;107:176-191. DOI:10.1016/j.addr.2016.05.020.

Lemarchand C, Couvreur P, Besnard M, Costantini D, Gref R. Novel polyester-polysaccharide nanoparticles. Pharm Res. 2003;20(8):1284-1292.

Lemarchand C, Gref R, Couvreur P. Polysaccharide-decorated nanoparticles. Eur J Pharm Biopharm. 2004;58(2):327-341.

Lenaerts V, Couvreur P, Christiaensleyh D, et al. Degradation of poly (isobutyl cyanoacrylate) nanoparticles. Biomaterials. 1984;5:65-68.

Leroux JC. Editorial: Drug Delivery: Too Much Complexity, Not Enough Reproducibility? Angew Chem Int Ed Engl. 2017;56(48):15170-15171. DOI:10.1002/anie.201709002

Leyh $D$, Couvreur $P$, Lenaerts $V$, et al. Etude du mécanisme de dégradation des nanoaprticules de polycyanoacrylate d'alkyle. Labo-Pharm-Prob Tech. 1984;32:100-104.

Lherm C, Couvreur P, Loiseau P, et al. Unloaded polyisobutylcyanoacrylate nanoparticles: efficiency against bloodstream trypanosomes, J Pharm Pharmacol. 1987;39(8):650-652.

Li P, Dai YN, Zhang JP, et al. Chitosan-Alginate Nanoparticles as a Novel Drug Delivery System for Nifedipine. Int J Biomed Sci. 2008;4:221-228.

Li Z, Tan S, Li S, Shen Q, et al. Cancer drug delivery in the nano era: An overview and perspectives (Review). Oncol Rep. 2017;38(2):611-624. DOI:10.3892/or.2017.5718.

Li Y, Wang Y, Huang G, et al. Cooperativity principles in self-assembled nanomedicine. Chem Rev. 2018;1185359-5391. DOI:10.1021/acs.chemrev.8b00195

Lira MC, Santos-Magalhães NS, Nicolas V, et al. Cytotoxicity and cellular uptake of newly synthesized fucoidan-coated nanoparticles, Eur J Pharm Biopharm. 2011;79(1):162-170. doi: 10.1016/j.ejpb.2011.02.013.

Lopes M, Abrahim B, Veiga F, et al. Preparation methods and applications behind alginate-based particles. Expert Opin Drug Deliv. 2017;14(6):769-782. DOI:10.1080/17425247.2016.1214564.

Lourenco C, Teixeira M, Simoes S, et al. Steric stabilization of nanoparticles: size and surface properties. Int J Pharm. 1996;138:1-12.

Lowe P.H., Temple C.S. Calcitonin and insulin in isobutylcyanoacrylate nanocapules: protection against proteases and effect on intestinal absorption in rats. J Pharm Pharmacol. 1994;46:547-552.

Lu J, Wang J, Ling D. Surface Engineering of Nanoparticles for Targeted Delivery to Hepatocellular Carcinoma. Small. 2018;14(5). DOI: 10.1002/smll.201702037.

Ludwig A. The use of mucoadhesive polymers in ocular drug delivery. Adv Drug Deliv Rev. 2005;57(11):1595-639. 
Lundquist $P$, Artursson $P$. Oral absorption of peptides and nanoparticles across the human intestine: Opportunities, limitations and studies in human tissues. Adv Drug Deliv Rev. 2016;106:256-276.

Luque-Michel E, Imbuluzqueta E, Sebastián V, et al. Clinical advances of nanocarrier-based cancer therapy and diagnostics. Expert Opin Drug Deliv. 2017;14(1):75-92.

Maeda $\mathrm{H}$. The enhanced permeability and retention (EPR) effect in tumor vasculature: the key role of tumor-selective macromolecular drug targeting, Adv Enzyme Regul. 2001;41:189-207

Maeda $\mathrm{H}$. Toward a full understanding of the EPR effect in primary and metastatic tumors as well as issues related to its heterogeneity, Adv Drug Deliv Rev. 2015;91:3-6. doi:

10.1016/j.addr.2015.01.002.

Mahato RI. Challenges of turning nucleic acids into therapeutics. Adv Drug Deliv Rev. 2000;44(2-3):7980.

Maincent P, Devissaguet JP, Le Verge R, et al. Preparation and in vivo studies of a new drug delivery system. Appl Biochem Biotechnol. 1984;10,263-265.

Maincent P, Le Verge R, Sado P, et al. Disposition Kinetics and Oral Bioavailability of Vincamine-Loaded Polyalkyl Cyanoacrylate Nanoparticles. J Pharm Sci. 1986;75:955-958.

Malli S, Bories C, Bourge M, et al. Surface-dependent endocytosis of poly(isobutylcyanoacrylate) nanoparticles by Trichomonas vaginalis, Int J Pharm. 2018;548: 276-287. doi: 10.1016/j.ijpharm.2018.07.006

Matsumura Y, Maeda H. A new concept for macromolecular therapeutics in cancer chemotherapy: mechanism of tumoritropic accumulation of proteins and the antitumor agent smancs, Cancer Res. 1986;46(12 Pt 1):6387-6392.

Matuszak J, Baumgartner J, Zaloga J, et al. Nanoparticles for intravascular applications: physicochemical characterization and cytotoxicity testing, Nanomedicine (Lond). 2016;11(6):597616. doi: 10.2217/nnm.15.216.

Matuszak J, Dörfler P, Lyer S, et al. Comparative analysis of nanosystems' effects on human endothelial and monocytic cell functions, Nanotoxicology. 2018;12:957-974. doi: 10.1080/17435390.2018.1502375

Mejia-Ariza R, Graña-Suárez L, Berboom W, et al. Cyclodextrin-based supramolecular nanoparticles for biomedical applications. J Mater Chem B. 2017;5:36-52. DOI:10.1039/C6TB02776H.

Merkle HP. Drug delivery's quest for polymers: Where are the frontiers? Eur J Pharm Biopharm. 2015;97:293-303. DOI:10.1016/j.ejpb.2015.04.038.

Merle P, Camus P, Abergel A, et al. Safety and efficacy of intra-arterial hepatic chemotherapy with doxorubicin-loaded nanoparticles in hepatocellular carcinoma. ESMO Open. 2017a;2(4):e000238. DOI:10.1136/esmoopen-2017-000238.

Merle P, Bodoky G, Lopez Lopez C, et al. The Relive study investigator group. Abstract of the International Liver Cancer Association (ILCA) annual conference; 2017b 15-17 September; Seoul, South Korea. Abstract \# 0-020, page 13. Available from: https://www.ilca2017.org/programme/ [Accessed 25 September 2018]. 
Merle P, Pelletier G, Habersetzer F, et al. A multicentre, randomised, open-label study comparing the efficacy and safety of two doses of Doxorubicin TransdrugTM to best standard of care in patients with advanced Hepatocellular Carcinoma (HCC) after sorafenib. The relive study. P1334 J. Hepatology 2015;62(Supp. 2):S856 DOI:10.1016/S0168-8278(15)31513-0

Mesiha MS, Sidhom MB, Fasipe B. Oral and subcutaneous absorption of insulin poly(isobutylcyanoacrylate) nanoparticles. Int J Pharm. 2005;288(2):289-293.

Mi Y, Shao Z, Vang J, et al. Application of nanotechnology to cancer radiotherapy. Cancer Nanotechnol. 2016;7:11.Doi: 10.1186/s12645-016-0024-7.

Michaelis K, Hoffmann MM, Dreis S, et al. Covalent linkage of apolipoproteine to albumin nanoparticles strongly enhances drug transport into the brain. J Pharmacol Exp Ther. 2006;317(3):1246-1253.

Moghimi SM. Nanomedicine safety in preclinical and clinical development: focus on idiosyncratic injection/infusion reactions. Drug Discov Today. 2018;23(5):1034-1042. DOI:10.1016/j.drudis.2017.11.006

Moghimi SM, Peer D, Langer R. Reshaping the future of nanopharmaceuticals: ad iudicium, ACS Nano. 2011;5(11):8454-8458. doi: 10.1021/nn2038252

Mohammadi M, Ramezani M, Abnous $K$, et al. Biocompatible polymersomes-based cancer theranostics: Towards multifunctional nanomedicine. Int J Pharm. 2017;519(1-2):287-303. DOI:10.1016/j.ijpharm.2017.01.037.

Mokhtarzadeh A, Alibakhshi A, Hashemi M, et al. Biodegradable nano-polymers as delivery vehicles for therapeutic small non-coding ribonucleic acids. J Control Release. 2017;245:116-126. DOI:10.1016/j.jconrel.2016.11.017.

Monza da Silveira A, Ponchel G, Puisieux F, et al. Combined poly(isobutylcyanoacrylate) and cyclodextrins nanoparticles for enhancing the encapsulation of lipophilic drugs. Pharm Res. 1998;15(7):1051-1055.

Moroz E, Matoori S, Leroux JC. Oral delivery of macromolecular drugs: Where we are after almost 100years of attempts. Adv Drug Deliv Rev. 2016;101:108-121. DOI:10.1016/j.addr.2016.01.010

Mukhopadhyay P, Maity S, Mandal S, et al. Preparation, characterization and in vivo evaluation of $\mathrm{pH}$ sensitive, safe quercetin-succinylated chitosan-alginate core-shell-corona nanoparticle for diabetes treatment. Carbohydr Polym. 2018;182:42-51. DOI:10.1016/j.carbpol.2017.10.098.

Mundargi RC, Babu VR, Rangaswamy V, et al. Nano/micro technologies for delivering macromolecular therapeutics using poly(D,L-lactide-co-glycolide) and its derivatives. J Control Release. 2008;125(3):193-209.

Mura S, Couvreur P. Nanotheranostics for personalized medicine. Adv Drug Deliv Rev. 2012;64(13):1394-416. DOI:10.1016/j.addr.2012.06.006.

Mura S, Nicolas J, Couvreur P. Stimuli-responsive nanocarriers for drug delivery. Nat Mater. 2013;12(11):991-1003.DOI:10.1038/nmat3776.

Mura S, Couvreur $\mathrm{P}$, Combining imaging and drug delivery for the treatment of severe diseases. In: Mura S, Couvreur P, editors. Nanotheranostics for personalized medicine. [Place unknown]: World Scientific; 2016a. p. 1-6. DOI:10.1142/9789814713535_0001. 
Mura S, Couvreur P. Nanoteranostic for personalized medicine, World Scientific 2016b. DOI:10.1142/9741.

Mura S, Fattal E, Nicolas J. From Drug loaded poly(alkylcyanoacrylate) nanoparticles to squalene-based prodrug nanoparticles. J Drug targeting, This Volume

Murthy RSR, Reddy LH. Poly(Alkyl Cyanoacrylate) Nanoparticles for Delivery of Anti-Cancer Drugs. Amiji MM, editor. Nanotechnology for Cancer Therapy. Boca Raton (FL):Taylor and Francis Group; 2006. p.251-288.

Nakamura Y, Mochida A, Choyke PL, et al. Nanodrug Delivery: Is the Enhanced Permeability and Retention Effect Sufficient for Curing Cancer?, Bioconjug Chem. 2016;27(10):2225-2238.

Narvekar M, Xue HY, Eoh JY, et al. Nanocarrier for poorly water-soluble anticancer drugs--barriers of translation and solutions. AAPS PharmSciTech. 2014;15(4):822-33. DOI:10.1208/s12249-014-0107$\mathrm{x}$.

Nemati F, Duvernet $C$, Colin de Verdière A, et al. Some parameters influencing cytotoxicity of free doxorubicin and doxorubicin-loaded nanoparticles in sensitive and resistant leukemic murine cells: incubation time, number of nanoparticles per cell. Int J Pharm. 1994;102:55-62.

Nemati F, Dubernet $\mathrm{C}$, Fessi $\mathrm{H}$, et al. Reversion of multidrug resistance using nanoparticles in vitro : influence of the nature of the polymer. Int J Pharm. 1996;138:237-246.

Nicolas J, Bensaid F, Desmaële D, et al. Synthesis of highly functionalized poly (alkyl cyanoacrylate) nanoparticles by means of click chemistry. Macromolecules. 2008;41(22):8418-8428.

Nicolas J, Couvreur P. Synthesis of poly(alkyl cyanoacrylate)-based colloidal nanomedicines. Wiley Interdiscip Rev Nanomed Nanobiotechnol. 2009;1(1):111-127. DOI:10.1002/wnan.15

Nicolas J, Brambilla D, Carion O, et al. Quantum dot-loaded PEGylated poly(alkyl cyanoacrylate) nanoparticles for in vitro and in vivo imaging, Soft Matter 2011;7:6187-6193. Doi: 10.1039/ c1sm05529a

Nicolas J, Vauthier C. Poly(alkylcyanoacrylate) nanosystems. In A. Prokop, editor. Intracellular Delivery: Fundamentals and Applications, Fundamental Biomedical Technologies. [place unknown]: Springer Inc.; 2011 p. 225-250. DOI:10.1007/978-94-007-1248-5_9,

Nicolas J, Mura S, Brambilla D, et al. Design, functionalization strategies and biomedical applications of targeted biodegradable/biocompatible polymer-based nanocarriers for drug delivery. Chem Soc Rev. 2013;42:1147-1235.

Nicolas, J. Drug-Initiated Synthesis of Polymer Prodrugs: Combining Simplicity and Efficacy in Drug Delivery. Chem Mater. 2016;28:1591-1606.

Nicolas J, Couvreur P., Polymer nanoparticles for the delivery of anticancer drug. Med Sci. 2017;33:1117. DOI:10.1051/medsci/20173301003.

NTC 01655693: Efficacy and safety doxorubicin Transdrug study in patients suffering from advanced hepatocellular carcinoma

(ReLive). https://clinicaltrials.gov/ct2/show/record/NCT01655693?show locs=Y, Accessed 17/11/2018 
Ojha T, Pathak V, Shi Y, et al. Pharmacological and physical vessel modulation strategies to improve EPR-mediated drug targeting to tumors, Adv Drug Deliv Rev. 2017;119:44-60. doi: 10.1016/j.addr.2017.07.007.

Onxeo, Press release from 19 May 2014: http://www.onxeo.com/en/livatag-obtient-le-statut-fasttrack-de-la-fda-pour-le-traitement-du-cancer-primitif-du-foie/ accessed 19 september 2018

Onxeo, Press release from 11 septembre 2017 http://www.onxeo.com/en/onxeo-announces-top-lineresults-relive-phase-iii-study-livatag-advanced-hepatocellular-carcinoma/ accessed 8 November 2018,

Onxeo, Press Release from 17 Septembre 2017 : http://www.onxeo.com/fr/onxeo-announces-topline-results-relive-phase-iii-study-livatag-advanced-hepatocellular-carcinoma/ accessed 25 Septembre 2018

Oppenheim RC. Solid colloidal drug delivery systems: Nanoparticles. Int J Pharm. 1981;8:217-234.

Palazzo C, Ponchel G, Vachon JJ, et al. Obtaining non-spherical poly(alkylcyanoacrylate) nanoparticles by the stretching method applied with a marketed water-soluble film, Int J Polym Mater. 2017;66:416-424. doi: 10.1080/00914037.2016.1233420.

Park K. Facing the truth about nanotechnology in drug delivery. ACS Nano. 2013;7:7442-7447. DOI: 10.1012/nm404501g.

Park K. Questions on the role of the EPR effect in tumor targeting, J Control Rel. 2013;172, 391.

Park J, Park J, Pei Y, et al. Pharmacokinetics and biodistribution of recently-developed siRNA nanomedicines. Adv Drug Deliv Rev. 2016;104:93-109. DOI:10.1016/j.addr.2015.12.004.

Paterson J, Webster $\mathrm{Cl}$. Exploiting transferrin receptor for delivering drugs across the blood-brain barrier. Drug Discov Today Technol. 2016;20:49-52. DOI:10.1016/j.ddtec.2016.07.009.

Pelaz B., C. Alexiou, R. Alvarez-Puebla, et al. Diverse Applications of Nanomedicine. ACS Nano. 2017;11:2313-2381. DOI:10.1021/acsnano.6b06040

Peracchia MT, Vauthier C, Puisieux F, et al. Development of sterically stabilized poly(isobutyl 2cyanoacrylate) nanoparticles by chemical coupling of poly(ethylene glycol). J Biomed Mater Res. 1997a;34(3):317-326.

Peracchia MT, Vauthier C, Passirani C, et al. Complement consumption by poly(ethylene glycol) in different conformations chemically coupled to poly(isobutyl 2-cyanoacrylate) nanoparticles. Life Sci. 1997b;61(7):749-761.

Peracchia MT, Desmaële D., Couvreur P, et al. Synthesis of a novel (poly(MePEG-cyanoacrylate-coalkylcyanoacrylate) amphiphilic copolymer for nanoparticle technology. Macromolecules 1997c;30;656-851.

Peracchia MT, Fattal E, Desmaële D, et al. Stealth PEGylated polycyanoacrylate nanoparticles for intravenous administration and splenic targeting. J Control Release. 1999;60(1):121-128.

Peracchia MT, Harnisch S, Pinto-Alphandary $\mathrm{H}$, et al. Visualization of in vitro protein-rejecting properties of PEGylated stealth polycyanoacrylate nanoparticles, Biomaterials. 1999;20(14):12691275. 
Perrie Y. Gregory Gregoriadis: Introducing liposomes to drug delivery. J Drug Target. 2008;16(7):518519. DOI:10.1080/10611860802228376.

Pinto-Alphandary H, Andremont A, Couvreur P. Targeted delivery of antibiotics using liposomes and nanoparticles: research and applications. Int J Antimicrob Agents. 2000;13(3):155-168.

Pradines B, Bories C, Vauthier C, et al. Drug-free nanoparticles are active against Trichomonas vaginalis and non-toxic towards pig vaginal mucosa, Pharm Res. 2015a;32:1229-1236. doi: 10.1007/s11095-014-1528-7.

Pradines B, Djabourov M, Vauthier C, et al. Gelation and micellization behaviors of pluronic $\left.{ }^{\circledR}\right)$ F127 hydrogel containing poly(isobutylcyanoacrylate) nanoparticles specifically designed for mucosal application, Colloids Surf B Biointerfaces. 2015b;135:669-676. doi: 10.1016/j.colsurfb.2015.08.021.

Pridgen EM, Alexis F, Farokhzad OC. Polymeric Nanoparticle Drug Delivery Technologies for Oral Delivery Applications. Expert Opin Drug Deliv. 2015;12:1459-1473. DOI:10.1517/17425247.2015.1018175.

Puisieux F, Barratt G. Takeru Higuchi, the man and the scientist. Int J Pharm. 2011;418:3-5.

Qian ZM, Li H, Sun H, et al. Targeted drug delivery via the transferrin receptor-mediated endocytosis pathway. Pharmacol Rev. 2002;54(4):561-87.

Rajaonarivony M, Vauthier C, Couarraze G, et al. Development of a new drug carrier made from alginate. J Pharm Sci. 1993;82(9):912-917.

Ramon A.L., Bertrand J.R., De Martimprey H., et al. SiRNA associated with immunonanoparticles directed against cd99 antigen improve gene expression inhibition in vivo in Ewing's sarcoma. J Mol Recognition. 2013;26,318-329. DOI:10.1002/jmr.2276.

Raoul JL, Kudo M, Finn RS, et al. Systemic therapy for intermediate and advanced hepatocellular carcinoma: Sorafenib and beyond. Cancer Treat Rev. 2018;68:16-24. DOI:10.1016/j.ctrv.2018.05.006.

Reddy RH, Dubernet C, Mouelhi SL, et al. A new nanomedicine of gemcitabine displays enhanced anticancer activity in sensitive and resistant leukemia types. J Control Release. 2007;124 (1-2):2027.

Reddy LH, Couvreur P. Nanotechnology for therapy and imaging of liver diseases. J Hepatol. 2011;55(6):1461-1466. DOI: 10.1016/j.jhep.2011.05.039.

Ringsdorf H. Structure and properties of pharmacologically active polymers, J Polym Sci Polym Symp. 1975;51:135-153.

Ropert C, Lavignon M, Dubernet C, et al. Oligonucleotides encapsulated in $\mathrm{pH}$ sensitive liposomes are efficient toward Friend retrovirus. Biochem Biophys Res Commun. 1992;183(2):879-885. Erratum in: Biochem Biophys Res Commun. 1993a;192(2):982.

Ropert C, Malvy C, Couvreur P. Inhibition of the Friend retrovirus by antisense oligonucleotides encapsulated in liposomes: mechanism of action. Pharm Res. 1993b;10(10):1427-1433.

Ropert C, Lavignon M, Imbach JL, et al. Inhibition of the Friend retrovirus by antisense oligonucleotides. Ann New Yorl Acad Sci. 1992;660:334-335, 1992. DOI:10.1111/j.1749-6632.1992.tb21105.x 
Rosenblum D, Joshi N, Tao W, et al. Progress and challenges towards targeted delivery of cancer therapeutics, Nat Commun. 2018;9(1):1410. doi: 10.1038/s41467-018-03705-y.

Ross KA, Brenza YM, Binnebose AM, et al. Nano-Enabled Delivery of Diverse Payloads Across Complex Biological Barriers. J Control Release. 2015; 219, 548-559, 2015. DOI:10.1016/j.jconrel.2015.08.039.

Ryu JH, Lee S, Son S, et al. Theranostic nanoparticles for future personalized medicine. J Control Release. 2014;190:477-84. DOI:10.1016/j.jconrel.2014.04.027.

Satalkar P, Elger BS, Hunziker P, et al. Challenges of clinical translation in nanomedicine: A qualitative study. Nanomedicine. 2016a;12(4):893-900. DOI:10.1016/j.nano.2015.12.376

Satalkar P, Elger BS, Shaw DM. Defining Nano, Nanotechnology and Nanomedicine: Why Should It Matter? Sci Eng Ethics. 2016b;22(5):1255-1276

Saraiva C, Praça C, Ferreira R, et al. Nanoparticle-mediated brain drug delivery: Overcoming bloodbrain barrier to treat neurodegenerative diseases. J Control Release. 2016 Aug 10;235:34-47. DOI:10.1016/j.jconrel.2016.05.044.

Sarmento B, Ferreira D, Veiga F, et al. Characterization of insulin-loaded alginate nanoparticles produced by ionotropic pre-gelation through DSC and FTIR studies. Carbohydr Polym. 2006;66:1-7,.

Sarmento B, Ribeiro AJ, Veiga F, et al. Insulin-loaded nanoparticles are prepared by alginate ionotropic pre-gelation followed by chitosan polyelectrolyte complexation. J Nanosci Nanotechnol. 2007;7(8):2833-2841.

Schroeder A, Heller DA, Winslow MM, et al. Treating metastatic cancer with nanotechnology, Nat Rev Cancer. 2011;12(1):39-50. doi: 10.1038/nrc3180.

Schwab G, Duroux I, Chavany C, Hélène C, Saison-Behmoaras E. An approach for new anticancer drugs: oncogene-targeted antisense DNA. Ann Oncol. 1994;5 Suppl 4:55-58.

Scott DA, Charles AF, Waters ET. The oral administration of insulin derivatives. Trans Royal Soc Canada, Section V, Vol 26, pp. 287-293, 1932 (available at the British Labraey)

Shi J, Votruba AR, Farokhzad OC, et al. Nanotechnology in drug delivery and tissue engineering: from discovery to applications. Nano Lett. 2010;10(9):3223-3230. doi: 10.1021/nl102184c.

Shi J, Kantoff PW, Wooster R, et al. Cancer nanomedicine: progress, challenges and opportunities, Nat Rev Cancer. 2017;17(1):20-37. doi: 10.1038/nrc.2016.108.

Silva AC, Lopes CM, Sousa Lobo JM, et al. Nucleic Acids Delivery Systems: A Challenge for Pharmaceutical Technologists. Curr Drug Metab. 2015;16(1):3-16

Simon-Yarza T, Giménez-Marqués M, et al. A Smart Metal-Organic Framework Nanomaterial for Lung Targeting. Angew Chem Int Ed Engl. 2017;56(49):15565-15569. DOI:10.1002/anie.201707346.

Snipstad S, Berg S, Mørch Ý, et al. Ultrasound Improves the Delivery and Therapeutic Effect of Nanoparticle-Stabilized Microbubbles in Breast Cancer Xenografts, Ultrasound Med Biol. 2017;43(11):2651-2669. doi: 10.1016/j.ultrasmedbio.2017.06.029.

Sobot D, Mura S, Couvreur P. Haw can nanomedicines overcome cellular-based anticancer drug resistance. J Mater Chem. 2016;4, 5078-5100. DOI:10.1039/C6TB00900J 
Soma E, Attali P, Merle P. A clinically relevant case study: the development of Livatag ${ }^{\circledR}$ for the treatment of advanced hepatocellular carcinoma. In M.J. Alonso, N.S. Csaba, editors. RSC Drug Discovery Series $\mathrm{N}^{\circ} 22$ : Nanostructured Biomaterials for Overcoming Biological Barriers. Dorchester (UK): The Royal Society of Chemistry; 2012, p 591-600. DOI: 10.1039/9781849735292-00591.

Speiser PP. Non-liposomal nanocapsules, methodology and application. Front Biol. 1979;48:653-668.

Stanwix H. Patrick Couvreur: inspiring pharmaceutical innovation. Nanomedicine (Lond). 2014;9(6):759-7561. DOI:10.2217/nnm.14.24.

Stella VJ. My mentors. J Pharm Sci. 2001;90:969-978.

Stella B, Arpicco S, Peracchia MT, et al. Design of folic acid-conjugated nanoparticles for drug targeting. J Pharm Sci. 2000;89:1452-1464.

Stella B, Marsaud V, Arpicco S, et al. Biological characterization of folic acid-conjugated poly(H2NPEGCA-Co-HDCA) nanoparticles in cellular models. J Drug Target. 2007;15(2):146-153.

Stephenson ML, Zamecnik PC. Inhibition of Rous sarcoma viral RNA translation by a specific oligodeoxyribonucleotide. Proc Natl Acad Sci U S A. 1978;75(1):285-288.

Strebhardt K, Ullrich A. Paul Ehrlich's magic bullet concept: 100 years of progress. Nat Rev Cancer. 2008;8(6):473-480. DOI:10.1038/nrc2394.

Su H, Wang Y, Gu Y, et al. Potential applications and human biosafety of nanomaterials used in nanomedicine. J Appl Toxicol. 2018;38(1):3-24. DOI:10.1002/jat.3476.

Suarez S, Almutairi A, Christmann KL. Micro- and nanoparticles for treating cardiovascular disease. Biomaterials Sci. 2015;3:564-580.

Sulheim E, Baghirov $\mathrm{H}$, von Haartman $\mathrm{E}$, et al. Cellular uptake and intracellular degradation of poly(alkyl cyanoacrylate) nanoparticles, J Nanobiotechnology. 2016;14:1. doi: 10.1186/s12951-015-0156-7

Sulheim E, Iversen TG, To Nakstad V, et al. Cytotoxicity of poly(alkyl cyanoacrylate) nanoparticles. Int J Mol Sci. 2017;18(11):E2454. DOI: 10.3390/ijms18112454.

Suk JS, Xu Q, Kim N, et al. PEGylation as a strategy for improving nanoparticle-based drug and gene delivery. Adv Drug Deliv Rev. 2016;99:28-51. DOI: 10.1016/j.addr.2015.09.012.

Svenson S. Preclinical to clinical development of nanomedicines. In Torchilin V, editor. Handbook of Nanobiomedical Research Volume 3: Applications in diagnostic. Singapore (Singapore): World Scientific Publishing; 2014. p. 175-224. DOI: 10.1142/9789814520652 0058.

Szebeni J, Baranyi L, Savay S, et al. Liposome-induced pulmonary hypertension: properties and mechanism of a complement-mediated pseudoallergic reaction. Am J Physiol Heart Circ Physiol. 2000;279(3):H1319-1328.

Szebeni J, Fontana JL, Wassef NM, et al. Hemodynamic changes induced by liposomes and liposomeencapsulated hemoglobin in pigs: a model for pseudoallergic cardiopulmonary reactions to liposomes. Role of complement and inhibition by soluble CR1 and anti-C5a antibody. Circulation. 1999;99(17):2302-239.

Szebeni J. Complement activation-related pseudoallergy: A stress reaction in blood triggered by nanomedicines and biologicals. Molec Immunol. 2014; 61:163-173. DOI:10.1016/j.molimm.2014.06.038. 
Taxi J. (1960) Recherches en vue de l'identification au microscope électronique des cellules interstitielles de Cajal. In: Bargmann W, Peters D, Wolpers C, editors. Verhandlungen Band II / Biologisch-Medizinischer Teil. Springer (Berlin, Heidelberg); 1960. p. 440-443. DOI:10.1007/978-3662-22058-0_111

Theek B, Baues M, Ojha T, et al. Sonoporation enhances liposome accumulation and penetration in tumors with low EPR, J Control Release. 2016;231:77-85. doi: 10.1016/j.jconrel.2016.02.021.

Thorn CF, Oshiro C, Marsh S, Hernandez-Boussard T, McLeod H, Klein TE, Altman RB. Doxorubicin pathways: pharmacodynamics and adverse effects. Pharmacogenet Genomics. 2011;21(7):440446. DOI:10.1097/FPC.0b013e32833ffb56

Tinkle S, McNeil SE, Mühlebach S, et al. Nanomedicines: addressing the scientific and regulatory gap. Ann N Y Acad Sci. 2014;1313:35-56. DOI:10.1111/nyas.12403.

Treupel L, Poupon MF, Couvreur P, et al. Doxorubicin carried in nanospheres and the reversal of multidrug resistance in tumor cells. CR Acad Sci Ser III. 1991;313:171-174.

Toub N, Malvy C, Fattal E, et al. Innovative nanotechnologies for the delivery of oligonucleotides and siRNA. Biomed Pharmacother. 2006;60(9):607-620

Toub N, Bertrand JR, Malvy C, et al. Antisense oligonucleotide nanocapsules efficiently inhibit EWSFli1 expression in a Ewing's sarcoma model, Oligonucleotides. 2006;16(2):158-168.

Tyler B, Gullotti D, Mangraviti A, Utsuki T, Brem H. Polylactic acid (PLA) controlled delivery carriers for biomedical applications. Adv Drug Deliv Rev. 2016;107:163-175. DOI:10.1016/j.addr.2016.06.018.

Valent P, Groner B, Schumacher U, et al. Paul Ehrlich (1854-1915) and His Contributions to the Foundation and Birth of Translational Medicine. J Innate Immun. 2016;8(2):111-120. DOI:10.1159/000443526.

van Hoogevest P, Liu X, Fahr A. Drug delivery strategies for poorly water-soluble drugs: the industrial perspective. Expert Opin Drug Deliv. 2011;8(11):1481-1500. DOI: 10.1517/17425247.2011.614228.

Varna $M$, Juenet $M$, Bayles $R$, et al. Nanomedicine as a strategy to fight thrombotic diseases. Future Sci OA. 2015;1(4):FSO46. DOI:10.4155/fso.15.46.

Vauthier C, Seiller M, Weingarten C, et al. Contribution to the development of oral dosage form for insulin delivery. STP Pharma Sciences. 1999;9:391-396.

Vauthier C, Dubernet C, Fattal E, et al. Poly(alkylcyanoacrylates) as biodegradable materials for biomedical applications. Adv Drug Delivery Rev. 2003a;55:519-548.

Vauthier C, Dubernet C, Chauvierre C, Brigger I, Couvreur P. Drug delivery to resistant tumors: the potential of poly(alkyl cyanoacrylate) nanoparticles. J Control Release. 2003b;93(2):151-160.

Vauthier C, Labarre D, Ponchel G. Design aspects of poly(alkylcyanoacrylate) nanoparticles for targeted drug delivery. J Drug Target. 2007;15:641-663.

Vauthier C, Zandanel C, Ramon AL. Chitosan-based nanoparticles for in vivo delivery of interfering agents including siRNA. Curr Opin Colloid Interf Sci. 2013;18:406-418. DOI:10.1016/j.cocis.2013.06.005. 
Vauthier C. Methods for the Preparation of Nanoparticles by Polymerization. In Vauthier C, Ponchel G, editors. Polymer nanoparticles for nanomedicines. Cham (Switzerland): Springer2016. p. 123-157.

Venditto VJ, Szoka FC Jr. Cancer nanomedicines: so many papers and so few drugs! Adv Drug Deliv Rev. 2013;65(1):80-88. DOI: 10.1016/j.addr.2012.09.038.

Venkatesan J, Anil S, Kim S-K, et al. Seaweed Polysaccharide-Based Nanoparticles: Preparation and Applications for Drug Delivery. Polymers. 2016;8(2):30. DOI:10.3390/polym8020030

Ventola CL. Progress in Nanomedicine: Approved and Investigational Nanodrugs. P T. 2017;42(12):742755

Verrecchia T, Huve P, Bazile D, et al. Adsorption/desorption of human serum albumin at the surface of poly(lactic acid) nanoparticles prepared by a solvent evaporation process. J Biomed Mater Res. 1993;27(8):1019-1028.

von Maltzahn G, Park JH, Lin KY, et al. Nanoparticles that communicate in vivo to amplify tumour targeting, Nat Mater. 2011;10(7):545-552. doi: 10.1038/nmat3049.

Vranckx H, Demoustier M, Deleers M. A new nanocapsule formulation with hydrophilic core: Application to the oral administration of salmon calcitonin in rats. Eur J Pharm Pharmacol. 1996;42:345-347.

Wang D, Qian J, Ding F. Recent advances in engineered chitosan-based nanogels for biomedical applications. J Mater Chem B. 2017; 5:6986-7007. DOI:10.1039/C7TB01624G

Wankar J, Salzano G, Pancani E, et al. Efficient loading of ethionamide in cyclodextrin-based carriers offers enhanced solubility and inhibition of drug crystallization. Int J Pharm. 2017;531(2):568-576. DOI:10.1016/j.ijpharm.2017.05.041.

Watnasirichaikul S, Davies NM, Rades T, et al. Preparation of biodegradable insulin nanocapsules from biocompatible microemulsions. Pharm Res. 2000;17(6):684-689.

Weingarten C, Moufti A, Delattre J, et al. Protection of insulin from degradation by its association to liposomes. Int J Pharm. 1985;26:251-257. DOI:10.1016/0378-5173(85)90234-0.

Wicki A, Witzigmann D, Balasubramanian V, et al. Nanomedicine in cancer therapy: challenges, opportunities, and clinical applications. J Control Release. 2015;200:138-57. DOI:10.1016/j.jconrel.2014.12.030.

Wohlfart S, Gelperina S, Kreuter J. Transport of drugs across the blood-brain barrier by nanoparticles. J Control Release. 2012;161(2):264-73. DOI:10.1016/j.jconrel.2011.08.017.

Wong CY, Al-Salami H, Dass CR. Potential of insulin nanoparticle formulations for oral delivery and diabetes treatment. J Control Release. 2017;264:247-275. DOI:10.1016/j.jconrel.2017.09.003.

Yang X, Shi X, D'arcy R, et al. Amphiphilic polysaccharides as building blocks for self-assembled nanosystems: molecular design and application in cancer and inflammatory diseases. J Control Release. 2018;272:114-144. DOI:10.1016/j.jconrel.2017.12.033.

Yordanov GG. Poly(alkylcyanoacrylate) nanoparticles as drug carriers: 33 years later. Bulg J Chem. 2012;1:61-73. 
Yu K, Lai BF, Foley JH, et al. Modulation of complement activation and amplification on nanoparticle surfaces by glycopolymer conformation and chemistry. ACS Nano. 2014;8(8):7687-7703. DOI: $10.1021 / \mathrm{nn} 504186 \mathrm{~b}$.

Zandanel C, Legouffe R, Trochon-Joseph V, et al. Biodistribution of polycyanoacrylate nanoparticles encapsulating doxorubicin by Matrix-Assisted Laser Desorption lonization (MALDI) Mass Spectrometry Imaging (MSI). J Drug Deliv Sci Technol. 2018;47:55-61. DOI: 10.1016/j.jddst.2018.06.023.

Zhang $\mathrm{X}$, Xing $\mathrm{H}$, Zhao $\mathrm{Y}$, et al. Pharmaceutical dispersion techniques for dissolution and bioavailability enhancement of poorly water-soluble drugs. Pharmaceutics. 2018;10(3):E74. DOI: 10.3390/pharmaceutics10030074.

Zhao L, Liu A, Sun M, et al. Enhancement of oral bioavailability of puerarin by polybutylcyanoacrylate nanoparticles. J Nanomater. 2011;Article ID 126562. DOI:10.1155/2011/126562.

Zhou $Q$, Sun $X$, Zeng $L$, et al.. A randomized multicenter phase II clinical trial of mitoxantrone-loaded nanoparticles in the treatment of 108 patients with unresected hepatocellular carcinoma. Nanomedicine 2009;5:419-423, 2009. DOI:10.106/J.Nano.2009.01.009.

Zhou Y, Peng Z, Seven ES, et al.. Crossing the blood-brain barrier with nanoparticles. J Control Release 2018;270:290-303. DOI: 10.1016/j.jconrel.2017.12.015. 